\title{
Blocking Notch3 Signaling Abolishes MUC5AC Production in Airway Epithelial Cells from
}

\section{Asthmatics}

Andrew T Reid ${ }^{1,2}$, Kristy S Nichol',3, Punnam Chander Veerati ${ }^{2,3}$, Fatemeh Moheimani ${ }^{1,2}$, Anthony Kicic ${ }^{4,5,6,7,8}$, Stephen M Stick ${ }^{4,5,6,7}$, Nathan W Bartlett ${ }^{1,2}$, Chris L Grainge ${ }^{2,3,9}$, Peter A B Wark $^{2,3,9}$, Philip M Hansbro ${ }^{1,2}$, Darryl A Knight ${ }^{1,2,10}$

1. School of Biomedical Sciences and Pharmacy, University of Newcastle, Callaghan, NSW, Australia.

2. Priority Research Centre for Healthy Lungs, Hunter Medical Research Institute, The University of Newcastle, New South Wales, Australia.

3. School of Medicine and Public Health, University of Newcastle, Callaghan, NSW

4. School of Paediatrics and Child Health, University of Western Australia, Nedlands, 6009, Western Australia, Australia.

5. Telethon Kids Institute, University of Western Australia, Nedlands, 6009, Western Australia, Australia.

6. Department of Respiratory Medicine, Princess Margaret Hospital for Children, Perth, 6001, Western Australia, Australia.

7. Centre for Cell Therapy and Regenerative Medicine, School of Medicine and Pharmacology, University of Western Australia, Nedlands, 6009, Western Australia, Australia.

8. Occupation and Environment, School of Public Health, Curtin University, Bentley, 6102, Western Australia, Australia. 
9. Department of Respiratory and Sleep Medicine, John Hunter Hospital, Newcastle, New South Wales, Australia.

10. Department of Anesthesiology, Pharmacology and Therapeutics, University of British Columbia, Vancouver, Canada.

Author Contributions: A.R. designed and performed experiments, analyzed results, and wrote the manuscript. K.N. and P.V. helped with methodology, performed experiments and analyzed results. F.M., A.K., S.S. and N.B. helped design experiments and reviewed the manuscript. P.W. provided primary human bronchial epithelial cells and reviewed the manuscript. C.G. and P.H. helped conceptualize design of the project, helped interpret data and reviewed the manuscript. D.K. helped conceptualize project design, supervised the project, interpreted results and reviewed the manuscript.

Correspondence to: Andrew Reid, Hunter Medical Research Institute, New Lambton Heights 2305, Australia. Tel.: +61 240420108 E-mail: Andrew.reid@newcastle.edu.au

Short Running Head: Notch3 regulates MUC5AC production in airway

Word Count: 3,914 words

This article has an online data supplement, which is accessible from this issue's table of content online at www.atsjournals.org. 


\begin{abstract}
Rationale: In asthma, goblet cell numbers are increased within the airway epithelium, perpetuating the production of mucus that is more difficult to clear and results in airway mucus plugging. Notch1, 2 or 3, or a combination of these have been shown to influence differentiation of airway epithelial cells. How the expression of specific Notch isoforms differs in fully differentiated adult asthmatic epithelium and whether Notch influences mucin production following differentiation is currently unknown.
\end{abstract}

Objectives: We aimed to quantify different Notch isoforms in the airway epithelium of severe asthmatics and to examine the impact of Notch signaling on mucin MUC5AC. Human lung sections and primary bronchial epithelial cells from asthmatics and non-asthmatics were used in this study.

Methods: Primary bronchial epithelial cells were differentiated at air-liquid interface for 28 days. Notch isoform expression was analyzed by Taqman qPCR. Immunohistochemistry was used to localize and quantify Notch isoforms in human airway sections. Notch signaling was inhibited in vitro using dibenzazepine or Notch3-specific small interfering RNA, followed by analysis of MUC5AC.

Measurements and Main Results: NOTCH3 was highly expressed in asthmatic airway epithelium compared to non-asthmatic. Dibenzazepine significantly reduced MUC5AC production in air-liquid interface cultures of primary bronchial epithelial cells, concomitant with a suppression of NOTCH3 intracellular domain protein. Specific knockdown using NOTCH3 siRNA recapitulated the dibenzazepine-induced reduction in MUC5AC. 
Conclusions: We demonstrate that NOTCH3 is a regulator of MUC5AC production. Increased NOTCH3 signaling in the asthmatic airway epithelium may therefore be an underlying driver of excess MUC5AC production.

Word Count: 246 words

Keywords: Notch Signaling, Airway Epithelium, Mucus, MUC5AC, Pharmacological Inhibition. 
Mucus overproduction is one of many irregularities typically associated with inflammatory airway diseases asthma, chronic obstructive pulmonary disease (COPD) and bronchiectasis. When coupled with increases in viscosity, it is linked to defective mucociliary clearance and the formation of mucus plugs that cause airflow obstruction $(1,2)$. Two major gel-forming mucins exist in the airway mucus layer, MUC5AC and MUC5B. There is now strong evidence that submucosal glands and distal airways are the predominant sites of MUC5B expression, whilst proximal and cartilaginous airway epithelia are sites of both MUC5AC and MUC5B expression in the normal human lung $(3,4)$. Production of MUC5AC increases in patients with asthma (5), whereas MUC5B production varies. Levels of MUC5AC directly correlate with mucus viscoelasticity and airway mucus accumulation indicating that MUC5AC over-production is a driver of disease in asthma (6).

The NOTCH family of proteins, Notch1-4, are single-pass membrane receptor proteins responsible for regulating cell proliferation, differentiation and cell death (7). Numerous studies have demonstrated that $\mathrm{NOTCH}$ signaling controls goblet cell differentiation within the airway epithelium both in humans and mice (8-11). Notch signaling is activated via ligand-induced cleavage events, the final of which is facilitated by gamma-secretase leading to the nuclear translocation of the Notch intracellular domain (NICD) and subsequent gene expression (12). Signaling through the Notch1, 2 and 3 isoforms can determine whether airway epithelial cells differentiate to become goblet cells or ciliated cells $(10,13,14)$. Pharmacological inhibition of Notch signaling prevents airway basal cells from differentiating into goblet cells $(10,13)$. To date very few studies have investigated Notch isoform expression and signaling in the fully differentiated airway epithelium and the impact, if any, of asthma on these parameters. 
We hypothesized that Notch signaling is dysregulated in differentiated airway epithelial cells from asthmatics driving excess MUC5AC production. To investigate this we used air-liquid interface (ALI) cultures of primary bronchial epithelial cells (pBECs) from asthmatics and non-asthmatics (15). We show that the airway epithelium of asthmatics exhibits increased NOTCH3 and decreased NOTCH1 expression. Furthermore, inhibition of the NOTCH3 intracellular domain (NICD3) reduces mucin production in epithelial cell cultures from asthmatics and non-asthmatics grown at ALI. Notch3 appears to be a regulator of mucin production within the airway epithelium and its expression and activity is increased in asthma. Future studies targeting Notch3 may reveal its viability as a target to treat airways diseases where mucus hypersecretion is a pathological feature.

\section{Methods}

\section{Study approvals}

All experiments were conducted in accordance with Hunter New England Area Health Service Ethics Committee and University of Newcastle Safety Committee (85/2012) approvals.

\section{pBEC collection}

pBECs were obtained from individuals clinically assessed as asthmatic $(n=11)$ or non-asthmatic, all of whom were non-smokers $(n=11)$ (Table 1). Asthmatics had a documented history of bronchial hyperresponsiveness and were defined as severe asthmatic according to GINA guidelines. Individuals underwent fiber-optic bronchoscopy as previously described (16). Briefly, brushings were made from $3^{\text {rd }}$ generation bronchi and airway epithelial cells were isolated, cultured and passaged as previously described (17). Minimally-immortalized bronchial epithelial cells (BCi-Ns1.1) were donated by Prof. RG Crystal (18). 
pBEC cell culture and pharmacological inhibition

Cells were maintained in bronchial epithelial cell growth medium (BEGM; Lonza) as previously described (17). Cells were maintained at ALI for 25 days prior to pharmacological treatment with dibenzazepine (DBZ) (YO-01027; Selleck Chemicals, TX, USA) (online supplement). DBZ which is a highly selective gamma-secretase inhibitor was used at concentrations up to $10 \mu \mathrm{M}$ based on Notch inhibition studies in breast cancer cells (19). Cells were harvested for RNA, protein or fixed in 10\% Formalin (Lomb Scientific, NSW, Australia) for histology.

\section{BCI-Ns1.1 cell culture and siRNA transfection}

BCI-Ns1.1 cells, derived from primary bronchial epithelial cells were used for siRNA transfections experiments due their documented ease of transfection (20). Furthermore, these cells recapitulate the cell responses witnessed in our primary cell cohorts. BCi-NS1.1 cells were maintained in BEGM containing penicillin-streptomycin $(100 \mathrm{U} / \mathrm{mL}-100 \mu \mathrm{g} / \mathrm{mL}$ final) and Amphotericin $(2.5 \mu \mathrm{g} / \mathrm{mL}$ final) until confluent. Cells were transfected as per manufacturer's instructions using Notch3 siRNA (s9640; Thermo Fisher Scientific, MA, USA), Silencer Select negative control siRNA (4390843; Thermo Fisher Scientific), or media control (online supplement). 0.4ng/mL or $25 \mathrm{ng} / \mathrm{mL}$ recombinant human epidermal growth factor (rhEGF) (Lonza) were supplemented in media for standard culture and mucus generating culture respectively.

\section{Human lung tissue immunohistochemistry and colorimetry}

Human lung sections from 6 asthmatics and 6 non-asthmatics (University of British Columbia, BC, Canada), were subjected to immunohistochemical staining (IHC) (online supplement). A minimum of 4-5 airways were analyzed for each of the 12 donors. A maximum of 5 images were taken randomly per individual airway for analysis and were subjected to color deconvolution as 
previously described (21) (online supplement). Each data point represents mean staining intensity of each airway analyzed.

Air-liquid interface protein extraction and immunoblotting

ALI cell protein was extracted in ice-cold lysis buffer and subjected to immunoblotting as previously described (21). Membranes were blocked and incubated with primary antibodies; antiNOTCH3 $(0.2 \mu \mathrm{g} / \mathrm{mL})$, anti-NOTCH1 $(0.2 \mu \mathrm{g} / \mathrm{mL})$, or anti- $\beta$ actin $(\mathrm{ab} 8227$; Abcam) $(0.05 \mu \mathrm{g} / \mathrm{mL})$ (online supplement). Densitometry reported as ratio of band of interest to respective ACTB and normalized to Non-asthmatic control via ImageLab 6.0.1 software (Bio-Rad, CA, USA).

IHC, immunofluorescence and Alcian blue/PAS staining in ALI cultures

ALI membranes were stained with alcian blue and periodic acid Schiff (PAS) or IHC using anti-

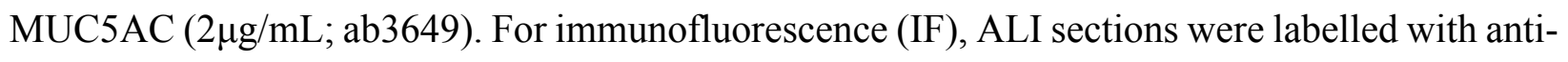
NOTCH1 or anti-NOTCH3 in combination with anti-MUC5AC. Fluorescent secondary antibodies; donkey anti-rabbit alexafluor-488 (A-21207; Invitrogen, CA, USA) and donkey antimouse alexafluor-594 (A-21203; Invitrogen) were used to visualize Notch and MUC5AC proteins respectively. Semi-quantitative assessment of positively stained alcian blue/PAS overlap or DAB labeled MUC5AC area was made via color deconvolution (online supplement).

\section{Real-time quantitative $R T-q P C R$}

Quantitative PCR (qPCR) targeting NOTCH1 (Hs01062014_m1), NOTCH2 (Hs01050702_m1), NOTCH3 (Hs01128537_m1), NOTCH4 (Hs00965889_m1), SPDEF (Hs00171942_m1), HES2 (Hs01021800_g1) and MUC5AC (Hs00873651_m1) was normalized to 18S ribosomal RNA (18S $r R N A$ ) (4318839; Thermo Fisher Scientific) as previously described (22). All qPCR results are 
presented as $\log _{2}$ fold change relative to control with statistics performed on $\Delta \Delta \mathrm{Ct}$ from independent biological replicates (23) (online supplement).

\section{MUC5AC ELISA}

MUC5AC-rich protein was obtained from cultures of Calu-3 human lung adenocarcinoma epithelial cells grown to ALI (24). Serial dilutions were made of Calu-3 apical surface fluid and linear MUC5AC standard curve was confirmed (data not shown). Indirect ELISA was performed as previously described targeting MUC5AC (25) (online supplement).

\section{Immunofluorescence and in-cell ELISA}

For IF, cells were washed and incubated overnight with anti-MUC5AC $(2 \mu \mathrm{g} / \mathrm{mL})$ followed by Alexa-fluor 594-conjugated donkey anti-mouse secondary antibody. Cells were counterstained with Hoechst 33342 (Sigma-Aldrich) $(0.6 \mu \mathrm{g} / \mathrm{mL})$. For in-cell ELISA, blocked cells were incubated with biotinylated anti-MUC5AC, streptavidin and TMB as above.

\section{Statistics}

Non-parametric Mann-Whitney U test (two-tailed, unpaired, exact method) (GraphPad PRISM software, CA, USA) was used to determine statistical significance between two groups. For multiple comparisons, Kruskal-Wallis method was utilized. Individual $P$ values are given, statistical significance was determined as $P<0.05$. 


\section{Results}

NOTCH3 expression is increased in Asthma

pBEC cultures, from 11 severe asthmatic and 11 non-asthmatic donors (Table 1 for demographics), were differentiated at ALI for 29 days. Both non-asthmatic and asthmatic pBECs expressed baseline levels of NOTCH1-3 but not NOTCH4 mRNA (figure 1A). NOTCH3 was elevated in ALI cultures from asthmatics $(P=0.003)$ compared to non-asthmatics. In contrast, NOTCH1 and NOTCH2 expression levels did not differ between both cohorts. NICD3, the cleaved/active Notch3 protein, was higher 1.6 fold $(P=0.032)$ in pBEC ALIs from the asthma group compared to nonasthmatic. Conversely, asthmatic NICD1 was significantly lower ( 0.3 fold; $P=0.008)$ compared to non-asthmatic (Figure 1B,C). NICD2 was difficult to detect within pBEC ALIs but showed no obvious difference between groups (Supplementary Figure E1). Based on these data we investigated Notch3 and Notch1 in human airways using IHC (Figure 1D). NOTCH3 was highly expressed in the airway epithelium of asthmatics, localizing to nuclei and the cell periphery. In agreement with pBEC data, colour segmentation analysis demonstrated a greater $(P=0.004)$ level of NOTCH3 protein in the epithelium of asthmatic airways (Figure 1E). NOTCH1, which exhibited diffuse localization throughout the cytoplasm in the epithelium of non-asthmatics, was expressed at a significantly lower level $(P<0.0001)$ in asthmatic airways.

Proximal localization of NOTCH1 and NOTCH3 with MUC5AC in ALI pBECs

NOTCH3 and NOTCH1 were analyzed for colocalization with MUC5AC using immunofluorescence (Figure 2). In pBEC ALIs from non-asthmatic donors NOTCH1 is strongly expressed and appears to localize in numerous columnar epithelial cells, often adjacent to MUC5AC producing goblet cells, potentially colocalizing with MUC5AC at the apical boundary of goblet and ciliated cells. NOTCH3 in these cells appears reduced in expression and evenly 
distributed across most of the epithelial layer, potentially appearing more intense around areas of MUC5AC containing goblet cells. NOTCH1 detection is lower in pBECs from asthma donors compared to non-asthma and does not localize solely to MUC5AC rich areas. Finally NOTCH3 appears much more intense in pBEC ALIs from asthma donors, present both adjacent to and within the same cells as MUC5AC, although does not show direct colocalization.

DBZ treatment reduces NOTCH3 activation in addition to $m R N A$ and protein expression in differentiated pBECs from asthmatics and non-asthmatics

Inhibition of Notch signaling was first confirmed in ALI pBECs following DBZ. In cells from non-asthmatics, NOTCH1 and 2 showed the same pattern of expression in which the lowest concentration of $\mathrm{DBZ}(0.1 \mu \mathrm{M})$ showed a trending reduction of each isoform by $\sim 40 \%$ its baseline value ( $P=0.056$ and 0,074 respectively) and higher concentrations of DBZ showed no appreciable difference to DMSO control (Figure 3A). In contrast, DBZ reduced NOTCH3 expression by $\sim 85 \%$ in ALI cultures from both asthmatics and non-asthmatics at $0.1,1$ and $10 \mu \mathrm{M}(P=0.049,0.008$ and 0.026 respectively). Immunoblotting confirmed the equivalent reduction in NICD3 protein in both non-asthmatic and asthmatic cells (Figure 3B); however, no concentration-dependent reduction in NICD3 was observed. In contrast, NICD1 protein levels did not differ from baseline for any concentration of DBZ in either cohort. To confirm reduction in Notch3 signaling activity we quantified HES2 mRNA, a specific downstream target of Notch3 signaling when stimulated by the Y-box 1 binding protein (YB-1) ligand (26). HES2 similar to NOTCH3 is significantly elevated $(P=0.016)$ in pBECs from asthma donors (Figure 3C). Treatment with DBZ significantly inhibited expression of HES2 in pBECs from both cohorts. PBECs from non-asthma donors showed a concentration-dependent reduction in HES2 as opposed to the asthma group. 


\section{DBZ Treatment Reduces Mucin Content in Differentiated pBECs}

pBECs from both donors showed regions of alcian blue/PAS overlap, appearing as a heavy dark blue/magenta stain (Figure 4A) (27). It was these alcian blue/PAS overlapping regions that were most heavily reduced in non-asthmatic $(P=0.0109)$ and trending less in asthmatic pBECs $(P=$ 0.1744) following treatment with DBZ (Figure 4A,B). This was further investigated by performing IHC targeting the individual mucin glycoprotein MUC5AC (Figure 4C). Control ALI cultures showed distinct labelling of MUC5AC within goblet cells in both non-asthmatics and asthmatics. In slight contrast to alcian blue/PAS data MUC5AC staining was significantly $(P=0.008)$ abolished in both asthma and non-asthma groups (Figure 4C,D).

\section{Inhibition of Notch Signaling Reduces MUC5AC Expression and Secretion}

Exposure to DBZ for 96 hours significantly reduced $M U C 5 A C$ mRNA in cells from nonasthmatics and asthmatics (Figure 5A). In order to determine whether the reduced production of MUC5AC protein within pBECs translated to reduced mucin secretion out of the cell we next performed ELISA targeting MUC5AC. At time points up to $72 \mathrm{~h}$ there was no significant reduction in MUC5AC for any concentration of DBZ (Data not shown). Following 96 hours of DBZ incubation there was a significant reduction in soluble MUC5AC observed in ALI cultures at all concentrations for non-asthma and $10 \mu \mathrm{M}$ for asthma with no concentration-dependent effect apparent (Figure 5B). In order to determine whether Notch was influencing regulators of goblet cell differentiation and mucin production we quantified expression of the key secretory cell regulator $S P D E F$. SPDEF mRNA was significantly reduced within cells from the same cultures as above following DBZ treatment (Figure 5C). 
We washed, fixed, embedded and sectioned cells from each cohort and performed immunofluorescent localization targeting MUC5AC to observe differences in secreted mucin architecture. MUC5AC glycoprotein adopted a filamentous appearance (Figure 5D; arrow) above the apical surface (Figure 5D; dashed line) of pBECs from asthmatics. This mucin was also tethered to the apical surface at numerous points. This was in contrast to minimal MUC5AC above the apical surface of pBECs from non-asthmatics.

NOTCH3 siRNA treatment significantly reduces MUC5AC production

siRNA-induced knockdown of NOTCH3 was used in conjunction with a previously established model in which MUC5AC production could be stimulated and analyzed within monolayer cultures (28). A total of 4 independent knockdown experiments were performed. NOTCH1 and NOTCH2 mRNA was unchanged following Notch3-siRNA treatment whereas as NOTCH3 expression was significantly reduced by $\sim 65 \%$ (Figure $6 \mathrm{~A}$ ). Full-length NOTCH3- and NICD3 protein levels were also significantly reduced following transfection (Figure 6B). Non-transfected and scrambledsiRNA transfected cells showed observable MUC5AC production when stimulated with $25 \mathrm{ng} / \mathrm{mL}$ EGF for 96 hours using IF and this labelling was lost in Notch3-siRNA treated cells. Similarly, quantification of MUC5AC by in-cell ELISA demonstrated significant increases in media control and scrambled-siRNA control cells following 96 hours EGF. The stimulatory effect of EGF on MUC5AC was abolished in Notch3-siRNA transfected cells.

\section{Discussion}

Mucus production is dysregulated in severe asthma $(1,5,6)$. The Notch signaling pathway is a key driver of goblet vs ciliated cell differentiation at the epithelium during development as well as in response to injury $(8-10,29)$. Here we have demonstrated that Notch signaling is imbalanced in 
differentiated airway epithelial cells from donors with asthma. Our study has shown that NOTCH3 is overexpressed in the airway epithelium of severe asthmatics, whilst NOTCH1 was significantly reduced compared to expression in airway epithelium of non-asthmatics. Treatment of ALI cultures with the Notch pathway inhibitor DBZ for 96 hours preferentially prevented cleavage of NICD3 over NICD1 and resulted in the dramatic loss of the gel-forming mucin MUC5AC. Additionally, transfection of immortalized pBECs with Notch3-specific siRNA significantly attenuated MUC5AC production. Thus we have provided evidence that Notch3 is a regulator of MUC5AC production and its dysregulation may contribute to the increased mucus observed in the airways of individuals with asthma.

Various Notch isoforms have been investigated in relation to chronic airway diseases and mucus dysregulation with the majority of these studies focusing on Notch1 $(8,30-32)$ and Notch2 $(8,13)$. Recently, Notch3 has been shown to regulate goblet cell hyperplasia in epithelial cells of the COPD airway in response to rhinovirus infection (14). We have shown that Notch3 is significantly increased in asthmatic pBECs, both in human lungs and differentiated under ALI culture. Currently, data is limited on how Notch3 regulates goblet cell hyperplasia and mucus production but our evidence suggests that upregulation of SPDEF may be a consequence of increased Notch3 signaling. Furthermore, data from this study in addition to data from Jing et al, (2018), suggests that Notch3 regulation of mucus production is independent of IL-13 signaling (14). The discrepancy observed between Notch1 mRNA (unchanged) and NICD1 protein (reduced) when comparing the asthma and non-asthma cohorts is likely due to blunted activation of Notch1 as the active NICD1 is primarily detected via western blotting and IHC (Figure1).

Previously, Notch3 has been reported to control the proliferation of airway basal cells through Jagged-ligand activation (33). During the establishment of a differentiated epithelium, Notch3 is 
believed to prime a pool of basal cells into intermediate secretory cells (club cells) that can then undergo differentiation into goblet or ciliated phenotypes through downstream Notch1/Notch2based signaling (33). In this study, we suggest that Notch3 exhibits an additional role in regulating MUC5AC production and secretion within, and adjacent to, goblet cells of the fully differentiated airway epithelium as MUC5AC stores are abolished following DBZ-induced Notch3 inhibition. Furthermore, this regulation was consistently observed in cells from asthmatics and nonasthmatics. In lung cancer cells, inhibition of Notch3 has been shown to prevent phosphorylation of mitogen-activated protein kinase (MAPK) a core component of the EGFR signaling pathway (34). As this pathway has also been implicated in the regulation of MUC5AC in airway epithelial cells (9), we speculate that Notch3 is necessary for MUC5AC production in pBECs by facilitating the phosphorylation of downstream MAPK. We feel that further studies can answer this mechanistic question with more vigor however.

The failure to observe significant reduction in alcian blue/PAS in pBECs from asthma donors compared to non-asthma may indicate that while MUC5AC production is abolished in both cohorts following DBZ, mucus production is not completely halted in asthma. We aim to identify which of these mucin components persist in pBECs from asthma donors following Notch inhibition in future studies.

DBZ is a potent gamma-secretase inhibitor and therefore should inhibit the cleavage of all Notch isoforms equivalently. Nonetheless, we consistently observed that the expression of the NICD3 domain was significantly reduced following DBZ treatment compared to NICD1. We are unsure as to why this reduction, or the reduction of downstream targets, was not concentration-dependent but this may be in part due to the differential inhibition of NICD1 and NICD3 cleavage. The discrepancy between NICD1 and NICD3 is likely due to non-canonical ligand-independent Notch 
activation previously described for the Notch1 isoform in human cells (35). This process involves ADAM metallopeptidase domain 17 (ADAM17)-stimulated cleavage which is hypothesized to preferentially release NICD1 from endosomal compartments independent of gamma-secretase activity $(35,36)$. Alternatively, as the NICD3 domain has a decreased half-life compared to NICD1 in airway epithelial cells it may not persist following DBZ treatment (37). Indeed, of all Notch isoforms only Notch3 has been shown to directly interact with E3-ubiquitin ligase in HEK293T cells, resulting in an increase in lysosomal degradation of the protein that can explain its reduced persistence (37). To date however, there have been no investigations of the stability of NICDs within airway epithelium or how stability may change according to disease status.

Notch3 has a shorter EGF-like domain and an incomplete transactivation domain compared to Notch1 and Notch2 (38). These domains regulate NICD activation and transcriptional activity explaining the weak transcriptional-activation potential described for NICD3. Indeed, compared to NICD1, NICD3 is a poor activator of the canonical Notch target HES1 which controls proliferation of stem cells $(39,40)$. The observation of increased Notch3 and decreased Notch1 in lung sections of donors with asthma was very intriguing. We hypothesize that the decrease seen in Notch1 protein is a direct result of increased Notch3 in the same cells and is due to Notch3 competing with Notch1 for binding to Notch cofactors/coactivators such as RBPJ and E2A. NICD1 is known to bind to the enhancer region of the Notch1 promoter with the help of such cofactors thus self-regulating Notch1 expression (41). Competition for binding to these cofactors by Notch3 would then reduce Notch1's ability to upregulate its own expression.

An alternative pathway of non-canonical Notch signaling, specific to Notch3, is stimulated by the Y-box binding protein (YB-1) (26). YB-1 is a cold-shock protein that binds to DNA/RNA and regulates DNA reparation, pre-mRNA splicing, mRNA stability and translation. YB-1 has also 
been shown to activate Notch3 signaling, stimulating $\gamma$-secretase cleavage (26). To date no in depth investigations have characterized roles of YB-1 in the asthmatic airway, however increased YB1/Notch3 signaling is linked with numerous inflammatory diseases such as asthma (26). YB-1 is chiefly expressed by immune cells and appears to selectively drive transcription of HES2. As such YB-1 is a potential target of future investigations into the role of Notch3 in regulating MUC5AC production is the asthmatic airway.

We have identified within human lung sections that $\mathrm{NOTCH} 3$ protein appears enriched in regions of the epithelium when NOTCH1 is low, and vice versa. Whether competition between NICD1 and NICD3 exists that activates or represses target genes in the airway epithelium needs further investigation. Tsao et al (2009), reported that inhibition of the Notch signaling pathway using Rbpjk and Pofut deficient mice as well as the gamma secretase inhibitor DAPT, resulted in the significant reduction of Scgb3a2 (secretory cell marker) in lungs during early development (11). Subsequent studies by this author (Tsao et al 2011), using post-natal mice showed that conditional inactivation of Notch signaling resulted in goblet cell metaplasia and mucin overproduction; thus highlighting that Notch-based control of secretory cell differentiation depends on differentiation status of the epithelium (32). In contrast, this study has found that the inhibition of Notch signaling in differentiated human airway epithelial cells leads to a dramatic reduction of MUC5AC as well as $S P D E F$ mRNA. It is possible that the conflicting results between this study and Tsao's are brought about by species specific differences in lung/epithelial morphology between human and mouse airways especially during the manipulation of key developmental pathways, or differences in the differentiation potential of cells in different studies of different age groups. In support of our data, a number of studies have shown that blocking Notch signaling in human airway epithelial cells leads to reduced numbers of secretory cells $(8,10)$. 
A recent study by Singanayagam et al, (2018) has found that fluticasone propionate (FP) treatment of a COPD-mouse model, or pBECs from COPD donors, in combination with rhinovirus (RV) infection significantly increases MUC5AC production in epithelial cells (42). Notch signaling is well known to control the function of glucocorticoid receptor-dependent gene expression (43). As Notch3 has also been shown to play a key role in mucus production during RV infection of epithelial cells from COPD donors, a process independent of IL-13 (14), Notch3 may therefore be a central regulatory protein that controls excess mucus production in airways diseases other than asthma.

Here we have shown that pBECs from severe asthmatics exhibit differential expression of Notch3 compared to non-asthmatics when cultured under identical conditions. Furthermore, MUC5AC was found to adopt a filamentous appearance above the apical cell surface and this tethering of mucin is analogous to what has been reported in cases of fatal asthma in vivo (44). In the current study it was necessary to treat differentiated cells basally so as to maintain cells at ALI for the full 96 hours. It is unclear how treatment of the basal surface has resulted in such a dramatic reduction of MUC5AC within cells at the apical surface, however there are likely two major factors. Firstly, DBZ is a small molecule inhibitor that can readily cross the cell plasma membrane and may diffuse readily across the small distance and into these apical cells. Secondly, the basolateral surfaces of many differentiated cells remain proximal to trans-well membrane pores and therefore would be permissive to DBZ diffusion.

siRNA-mediated knockdown of Notch3 results in significantly reduced MUC5AC production. Perrais et al (2002) reported that when NCI-H292 lung cancer cells were stimulated with $25 \mu \mathrm{g} / \mathrm{mL}$ EGF, MUC5AC apomucin becomes detectable by immunolocalization (28). We adopted this technique using minimally immortalized pBECs and combined it with immunofluorescent 
localization as well as in-cell ELISA. This definitively showed that the specific reduction of Notch3 prevents the stimulatory effect of EGF on MUC5AC production. Notch1 has been shown previously to play a role during EGFR signaling within NCI-H292 cells (9), suggesting that MUC5AC production may be under the control of more than one Notch isoform, and potentially involves fine alterations in the signaling pathways involved.

Future investigations using monoclonal antibodies against individual Notch isoforms will allow for the specific targeting and inhibition/activation of distinct Notch receptors in differentiated epithelial cell culture systems. This study highlights Notch-based regulation of EGF stimulated epithelial mucin production and reveals a potentially detrimental role for excess Notch3 in asthmatic airway epithelium. Notch3 may be a viable target to alleviate mucin production during asthma and other chronic respiratory diseases characterized by chronic overproduction of mucus.

$\underline{\text { Author disclosures are available with the text of this article at www.atsjournals.org. }}$ 


\section{References}

1. Malmström K, Lohi J, Sajantila A, Jahnsen FL, Kajosaari M, Sarna S, Mäkelä MJ. Immunohistology and remodeling in fatal pediatric and adolescent asthma. Respir Res 2017; $18: 94$.

2. Reid AT, Veerati PC, Gosens R, Bartlett NW, Wark PA, Grainge CL, Stick SM, Kicic A, Moheimani F, Hansbro PM, Knight DA. Persistent induction of goblet cell differentiation in the airways: Therapeutic approaches. Pharmacol Ther 2018; 185: 155-169.

3. Okuda K, Chen G, Subramani DB, Wolf M, Gilmore RC, Kato T, Radicioni G, Kesimer M, Chua M, Dang H, Livraghi-Butrico A, Ehre C, Doerschuk CM, Randell SH, Matsui H, Nagase T, O'Neal WK, Boucher RC. Localization of Secretory Mucins MUC5AC and MUC5B in Normal/Healthy Human Airways. Am J Respir Crit Care Med 2019; 199: 715-727.

4. Ma J, Rubin BK, Voynow JA. Mucins, Mucus, and Goblet Cells. Chest 2018; 154: 169-176.

5. Takeyama K, Fahy J, Nadel J. Relationship of Epidermal Growth Factor Receptors to Goblet Cell Production in Human Bronchi. Am J Respir Crit Care Med 2001; 163: 511-516.

6. Raclawska DS, Ttofali F, Fletcher AA, Harper DN, Bochner BS, Janssen WJ, Evans CM. Mucins and Their Sugars. Critical Mediators of Hyperreactivity and Inflammation. Annals of the American Thoracic Society 2016; 13: S98-S99.

7. Kopan R, Ilagan MXG. The Canonical Notch Signaling Pathway: Unfolding the Activation Mechanism. Cell 2009; 137: 216-233.

8. Lafkas D, Shelton A, Chiu C, de Leon Boenig G, Chen Y, Stawicki SS, Siltanen C, Reichelt M, Zhou M, Wu X, Eastham-Anderson J, Moore H, Roose-Girma M, Chinn Y, Hang JQ, Warming S, Egen J, Lee WP, Austin C, Wu Y, Payandeh J, Lowe JB, Siebel CW. 
Therapeutic antibodies reveal Notch control of transdifferentiation in the adult lung. Nature 2015; 528: 127-131.

9. Kang JH, Lee EH, Park SW, Chung IY. MUC5AC expression through bidirectional communication of Notch and epidermal growth factor receptor pathways. J Immunol 2011; 187: 222-229.

10. Gomi K, Arbelaez V, Crystal RG, Walters MS. Activation of NOTCH1 or NOTCH3 signaling skews human airway basal cell differentiation toward a secretory pathway. PLoS One 2015; 10: e0116507.

11. Tsao PN, Vasconcelos M, Izvolsky KI, Qian J, Lu J, Cardoso WV. Notch signaling controls the balance of ciliated and secretory cell fates in developing airways. Development 2009; 136: $2297-2307$.

12. De Strooper B, Annaert W, Cupers P, Saftig P, Craessaerts K, Mumm JS, Schroeter EH, Schrijvers V, Wolfe MS, Ray WJ, Goate A, Kopan R. A presenilin-1-dependent gammasecretase-like protease mediates release of Notch intracellular domain. Nature 1999; 398: $518-522$.

13. Danahay H, Pessotti AD, Coote J, Montgomery BE, Xia D, Wilson A, Yang H, Wang Z, Bevan L, Thomas C, Petit S, London A, LeMotte P, Doelemeyer A, Velez-Reyes GL, Bernasconi P, Fryer CJ, Edwards M, Capodieci P, Chen A, Hild M, Jaffe AB. Notch2 is required for inflammatory cytokine-driven goblet cell metaplasia in the lung. Cell Rep $2015 ; 10: 239-252$.

14. Jing Y, Gimenes JA, Mishra R, Pham D, Comstock AT, Yu D, Sajjan U. NOTCH3 contributes to rhinovirus-induced goblet cell hyperplasia in COPD airway epithelial cells. Thorax 2019; 74: 18-32. 
15. Pezzulo AA, Starner TD, Scheetz TE, Traver GL, Tilley AE, Harvey B-G, Crystal RG, McCray PB, Zabner J. The air-liquid interface and use of primary cell cultures are important to recapitulate the transcriptional profile of in vivo airway epithelia. $\mathrm{Am} J$ Physiol Lung Cell Mol Physiol 2011; 300: L25-L31.

16. Parsons KS, Hsu AC, Wark PA. TLR3 and MDA5 signalling, although not expression, is impaired in asthmatic epithelial cells in response to rhinovirus infection. Clin Exp Allergy 2014; 44: 91-101.

17. Wark PA, Johnston SL, Bucchieri F, Powell R, Puddicombe S, Laza-Stanca V, Holgate ST, Davies DE. Asthmatic bronchial epithelial cells have a deficient innate immune response to infection with rhinovirus. J Exp Med 2005; 201: 937-947.

18. Walters MS, Gomi K, Ashbridge B, Moore MAS, Arbelaez V, Heldrich J, Ding B-S, Rafii S, Staudt MR, Crystal RG. Generation of a human airway epithelium derived basal cell line with multipotent differentiation capacity. Respir Res 2013; 14: 135-135.

19. Harrison H, Farnie G, Howell SJ, Rock RE, Stylianou S, Brennan KR, Bundred NJ, Clarke RB. Regulation of Breast Cancer Stem Cell Activity by Signaling through the Notch4 Receptor. Cancer Res 2010; 70: 709-718.

20. Hayman TJ, Hsu AC, Kolesnik TB, Dagley LF, Willemsen J, Tate MD, Baker PJ, Kershaw NJ, Kedzierski L, Webb AI, Wark PA, Kedzierska K, Masters SL, Belz GT, Binder M, Hansbro PM, Nicola NA, Nicholson SE. RIPLET, and not TRIM25, is required for endogenous RIG-I-dependent antiviral responses. Immunol Cell Biol 2019; 97: 840-852.

21. Ruifrok AC, Johnston DA. Quantification of histochemical staining by color deconvolution. Anal Quant Cytol Histol 2001; 23: 291-299. 
22. Schuliga M, Jaffar J, Berhan A, Langenbach S, Harris T, Waters D, Lee PVS, Grainge C, Westall G, Knight D, Stewart AG. Annexin A2 contributes to lung injury and fibrosis by augmenting factor Xa fibrogenic activity. Am J Physiol Lung Cell Mol Physiol 2017; 312: L772-L782.

23. Schmittgen TD, Livak KJ. Analyzing real-time PCR data by the comparative C(T) method. Nat Protoc 2008; 3: 1101-1108.

24. Kreda SM, Okada SF, van Heusden CA, O'Neal W, Gabriel S, Abdullah L, Davis CW, Boucher RC, Lazarowski ER. Coordinated release of nucleotides and mucin from human airway epithelial Calu-3 cells. J Physiol 2007; 584: 245-259.

25. Bartlett NW, Walton RP, Edwards MR, Aniscenko J, Caramori G, Zhu J, Glanville N, Choy KJ, Jourdan P, Burnet J, Tuthill TJ, Pedrick MS, Hurle MJ, Plumpton C, Sharp NA, Bussell JN, Swallow DM, Schwarze J, Guy B, Almond JW, Jeffery PK, Lloyd CM, Papi A, Killington RA, Rowlands DJ, Blair ED, Clarke NJ, Johnston SL. Mouse models of rhinovirus-induced disease and exacerbation of allergic airway inflammation. Nat Med 2008; 14: 199-204.

26. Rauen T, Raffetseder U, Frye BC, Djudjaj S, Mühlenberg PJT, Eitner F, Lendahl U, Bernhagen J, Dooley S, Mertens PR. YB-1 acts as a ligand for Notch-3 receptors and modulates receptor activation. J. Biol. Chem. 2009; 284: 26928-26940.

27. Yamabayashi S. Periodic acid — Schiff — Alcian Blue: A method for the differential staining of glycoproteins. Histochem J 1987; 19: 565-571.

28. Perrais M, Pigny P, Copin M-C, Aubert J-P, Van Seuningen I. Induction of MUC2 and MUC5AC Mucins by Factors of the Epidermal Growth Factor (EGF) Family Is Mediated 
by EGF Receptor/Ras/Raf/Extracellular Signal-regulated Kinase Cascade and Sp1*. $J$ Biol Chem 2002; 277: 32258-32267.

29. Xing Y, Li A, Borok Z, Li C, Minoo P. NOTCH1 is Required for Regeneration of Clara Cells During Repair of Airway Injury. Stem Cells 2012; 30: 946-955.

30. Guseh JS, Bores SA, Stanger BZ, Zhou Q, Anderson WJ, Melton DA, Rajagopal J. Notch signaling promotes airway mucous metaplasia and inhibits alveolar development. Development 2009; 136: 1751-1759.

31. Boucherat O, Chakir J, Jeannotte L. The loss of Hoxa5 function promotes Notch-dependent goblet cell metaplasia in lung airways. Biol Open 2012; 1: 677-691.

32. Tsao P-N, Wei S-C, Wu M-F, Huang M-T, Lin H-Y, Lee M-C, Lin KM-C, Wang I-J, Kaartinen V, Yang L-T, Cardoso WV. Notch signaling prevents mucous metaplasia in mouse conducting airways during postnatal development. Development 2011; 138: 35333543.

33. Mori M, Mahoney JE, Stupnikov MR, Paez-Cortez JR, Szymaniak AD, Varelas X, Herrick DB, Schwob J, Zhang H, Cardoso WV. Notch3-Jagged signaling controls the pool of undifferentiated airway progenitors. Development 2015; 142: 258-267.

34. Haruki N, Kawaguchi KS, Eichenberger S, Massion PP, Olson S, Gonzalez A, Carbone DP, Dang TP. Dominant-Negative Notch3 Receptor Inhibits Mitogen-Activated Protein Kinase Pathway and the Growth of Human Lung Cancers. Cancer Res 2005; 65: 35553561.

35. Habets RA, Groot AJ, Yahyanejad S, Tiyanont K, Blacklow SC, Vooijs M. Human NOTCH2 Is Resistant to Ligand-independent Activation by Metalloprotease Adam17. J Biol Chem 2015; 290: 14705-14716. 
36. Palmer WH, Deng W-M. Ligand-Independent Mechanisms of Notch Activity. Trends Cell Biol 2015; 25: 697-707.

37. Jung J-G, Stoeck A, Guan B, Wu R-C, Zhu H, Blackshaw S, Shih I-M, Wang T-L. Notch3 Interactome Analysis Identified WWP2 as a Negative Regulator of Notch3 Signaling in Ovarian Cancer. PLoS Genet 2014; 10: e1004751.

38. Bellavia D, Checquolo S, Campese AF, Felli MP, Gulino A, Screpanti I. Notch3: from subtle structural differences to functional diversity. Oncogene 2008; 27: 5092-5098.

39. Beatus P, Lundkvist J, Oberg C, Lendahl U. The notch 3 intracellular domain represses notch 1-mediated activation through Hairy/Enhancer of split (HES) promoters. Development 1999; 126: 3925-3935.

40. Beatus P, Lundkvist J, Öberg C, Pedersen K, Lendahl U. The origin of the ankyrin repeat region in Notch intracellular domains is critical for regulation of HES promoter activity. Mech Dev 2001; 104: 3-20.

41. Yashiro-Ohtani Y, He Y, Ohtani T, Jones ME, Shestova O, Xu L, Fang TC, Chiang MY, Intlekofer AM, Blacklow SC, et al. Pre-tcr signaling inactivates notch1 transcription by antagonizing e2a. Genes Dev 2009;23(14):1665-1676.

42. Singanayagam A, Glanville N, Girkin JL, Ching YM, Marcellini A, Porter JD, Toussaint M, Walton RP, Finney LJ, Aniscenko J, Zhu J, Trujillo-Torralbo M-B, Calderazzo MA, Grainge C, Loo S-L, Veerati PC, Pathinayake PS, Nichol KS, Reid AT, James PL, Solari R, Wark PAB, Knight DA, Moffatt MF, Cookson WO, Edwards MR, Mallia P, Bartlett NW, Johnston SL. Corticosteroid suppression of antiviral immunity increases bacterial loads and mucus production in COPD exacerbations. Nat Commun 2018; 9: 2229. 
43. Revollo JR, Oakley RH, Lu NZ, Kadmiel M, Gandhavadi M, Cidlowski JA. HES1 Is a Master Regulator of Glucocorticoid Receptor-Dependent Gene Expression. Science Signaling 2013; 6: ra103-ra103.

44. Bonser LR, Zlock L, Finkbeiner W, Erle DJ. Epithelial tethering of MUC5AC-rich mucus impairs mucociliary transport in asthma. J Clin Invest 2016; 126: 2367-2371. 
Table and Figure captions:

TABLE 1: Demographics of asthmatic and non-asthmatic pBEC donors.

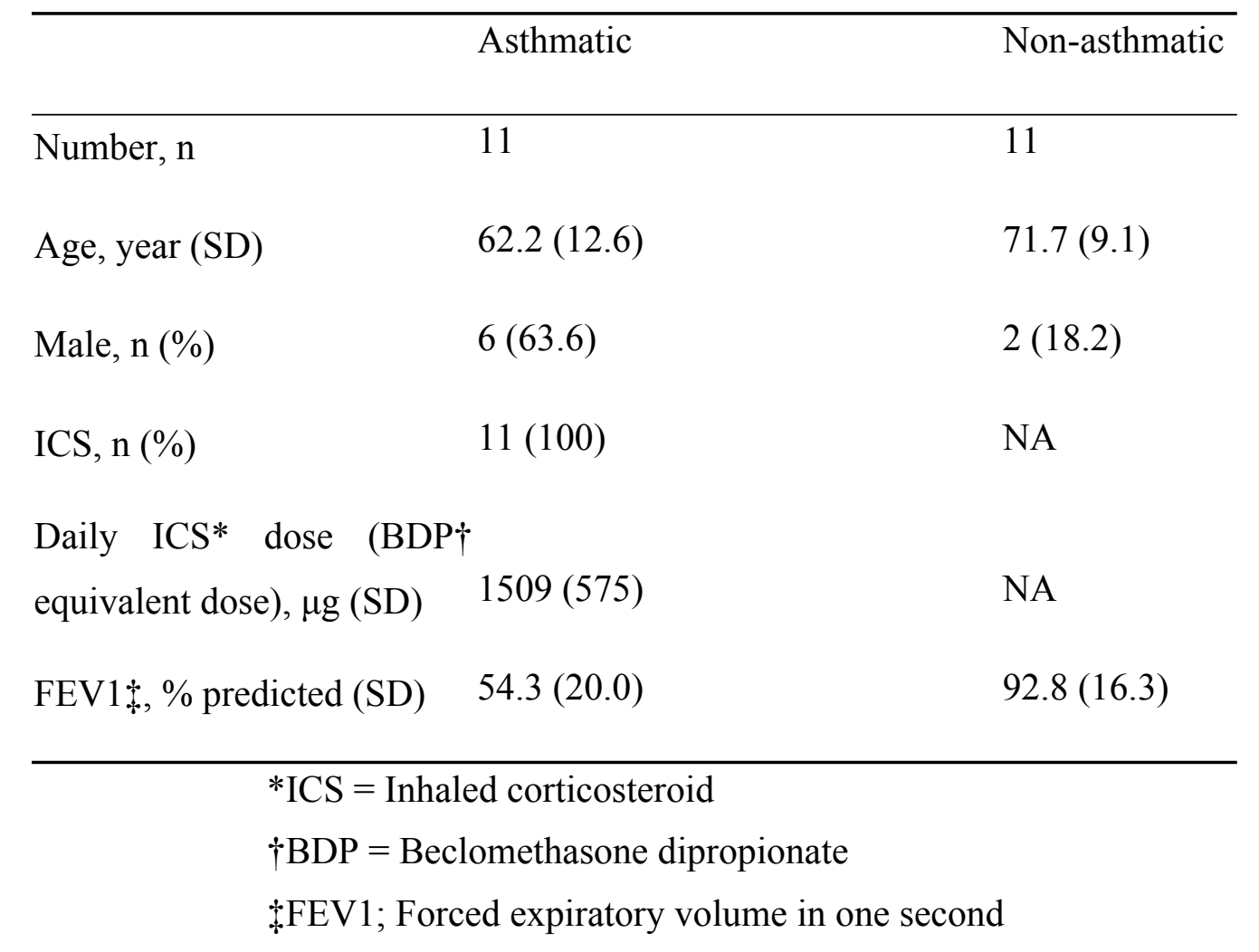


FIGURE 1: Notch3 expression is increased in asthma. (A) Quantitative real time (qRT) PCR analysis of NOTCH1-3 in differentiated primary bronchial epithelial cells (pBECs) from non-asthmatic and asthmatic donors. Data presented as box and whisker plots showing median and interquartile range (IQR) representative of 11 independent experiments (Mann-Whitney U test). (B) Western blots comparing Notch intracellular domain 3 (NICD3) and NICD1 in protein lysates from differentiated pBECs from 5 non-asthmatic and 5 asthmatic donors. $\beta$-actin (ACTB) staining served as loading control. (C) Western blot band densitometry for NICD3 and NICD1 normalized to $\beta$-catin . (D) Immunohistochemistry (IHC) targeting NOTCH3 or NOTCH1 in human lung tissue from asthmatic and non-asthmatic donors. Images representative of a minimum of 4-5 fields of view from 6 independent experiments. Scale bar: $20 \mu \mathrm{m}$. (E) Colour segmentation data for NOTCH3 and NOTCH1 IHC comparing asthmatic to non-asthmatic epithelial sections. Data presented as box-plots highlighting median stain $/ \mu \mathrm{m}^{2} /$ nuclei for all analysed images per donor (Mann-Whitney U test).

FIGURE 2: NOTCH1 and NOTCH3 are more strongly localized to areas adjacent to MUC5AC in differentiated ALI pBECs. NOTCH1 (green) is strongly expressed at areas adjacent to MUC5AC (red) expressing cells in ALI pBECs from non-asthmatic donors. NOTCH1 intensity is relatively lower in cells from donors with asthma. NOTCH3 is more widely and strongly localized in ALI pBECs from donors with asthma compared to non-asthma. NOTCH3 localization is also present within MUC5AC producing cells but fails to exhibit a colocalization signal. Scale $20 \mu \mathrm{m}$.

FIGURE 3: Dibenzazepine (DBZ) treatment significantly reduced Notch3 at $0.1,1$ and $10 \mu \mathrm{M}$ in differentiated primary bronchial epithelial cells (pBECs) from non-asthmatics (Non-As) 
and asthmatics (As) compared to DMSO (0.02\%) vehicle controls 'D'. (A) Quantitative real-time PCR analysis of NOTCH1-3 following DBZ treatment for 96 hours in pBECs from asthmatics and non-asthmatics differentiated at air-liquid interface (ALI) for 29 days. (B) Western blot analysis of NICD3 and NICD1 proteins following DBZ treatment for 96 hours in pBECs from both donor cohorts. $\beta$-actin (ACTB) staining served as loading control. Western blots are representative of a minimum of three independent experiments, each experiment conducted under identical conditions on the same day. (C) Expression (qPCR) of the Notch3 downstream target HES2, is significantly elevated in pBEC ALIs from asthma donors compared to non-asthma. Following DBZ treatment HES2 is significantly reduced in both non-asthma and asthma groups. Graphical data represent median from five independent experiments \pm IQR calculated for each donor group (Kruskal-Wallis test).

FIGURE 4: Notch signaling inhibition abolished MUC5AC production in differentiated primary bronchial epithelial cells (pBECs) compared to vehicle controls. (A) Alcian blue and periodic acid Schiff (PAS) staining analysis of pBECs at air-liquid interface (ALI) from asthmatics and non asthmatics treated with DMSO $(0.02 \%)$ vehicle control or $10 \mu \mathrm{M}$ DBZ for 96 hours. Scale bar: $25 \mu \mathrm{m}$. (B) Colour segmentation based semi-quantification of overlapping alcian blue/PAS area (\% total epithelial area) following treatment with dibezazepine (DBZ) or DMSO vehicle control. (C) IHC staining of mucin MUC5AC following treatment with DBZ treatment or DMSO vehicle control for 96 hours. Scale bar: $25 \mu \mathrm{m}$. (D) Colour segmentation based semi-quantification of 3,3'-Diaminobenzidine (DAB) labeled MUC5AC area (\% total epithelial area) following DBZ treatment. 
Graphical data represent median from five independent experiments + IQR calculated for each donor group (Kruskal Wallis test).

FIGURE 5: Notch signaling inhibition reduced MUC5AC expression and secretion in differentiated pBECs compared to DMSO (0.02\%) vehicle controls 'D'. (A) MUC5AC mRNA was measured using quantitative real-time (qRT) PCR following DBZ treatment at $0.1,1$ and $10 \mu \mathrm{M}$ concentrations, in pBECs at air-liquid interface (ALI) (asthmatic vs non-asthmatic). (B) ELISA was used to quantify MUC5AC protein in fluid taken from the apical surface of pBECs at ALI (asthmatic and non-asthmatic). (C) Expression of SAM Pointed Domain Containing ETS Transcription Factor (SPDEF) in pBECs at ALI treated with $0.1,1,10 \mu \mathrm{M}$ DBZ or DMSO vehicle control. (D) IF labeling of MUC5AC (red) in differentiated pBECs from asthmatics and non-asthmatics. MUC5AC routinely adopted a filamentous tethered appearance (arrow) above the cell surface (dashed line) in from asthmatics. Cell nuclei counterstained with DAPI. Graphical data represent median from five independent experiments + IQR calculated for each donor group (Kruskal Wallils test). Images representative of five independent experiments. Scale bar: $32 \mu \mathrm{m}$.

FIGURE 6: Specific NOTCH3 small-interfering RNA (siRNA) knockdown significantly reduces MUC5AC production in monolayer airway epithelial cells. (A) Quantitative realtime (qRT) PCR was used to determine levels of NOTCH1-3 mRNAs following siRNA knockdown (NOTCH3 vs scrambled control) in BCi-NS1.1 cells. (B) Western blots were used to assess knockdown of NOTCH3 full-length and NOTCH3 intracellular domain (NICD3) following NOTCH3 or scrambled control siRNA treatment. Western blots are representative of three independent experiments, each experiment conducted under identical conditions on the same day. (C) MUC5AC IF (red) was analysed in Notch3 
siRNA-transfected cells compared to scrambled control cells following treatment with $25 \mathrm{ng} / \mathrm{mL}$ recombinant human epidermal growth factor (rhEGF). Cell nuclei were counterstained with Hoechst 33342 (blue). Fluorescent images are representative of four independent experiments. Scale bar: $30 \mu \mathrm{m}$. (D) MUC5AC expression was quantified following transfection with NOTCH3 or scrambled siRNAs using in-cell ELISA (n=4). MUC5AC production was determined in the presence of $0.4 \mathrm{ng} / \mathrm{mL}$ or $25 \mathrm{ng} / \mathrm{mL}$ rhEGF. All graphical data represent average from four independent experiments + SD calculated for each group (Kruskal-Wallis test). 
A
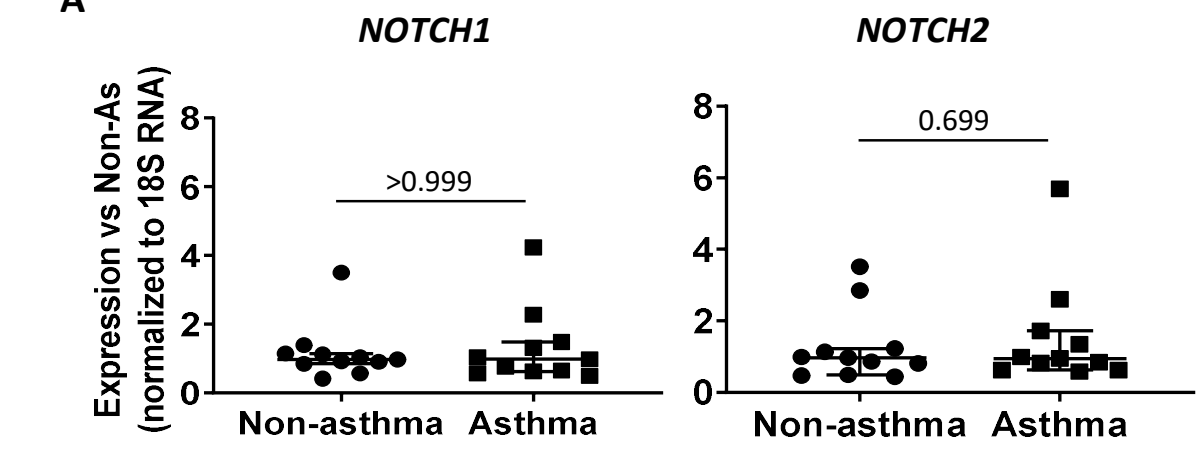

NOTCH3

Non-asthma Asthma
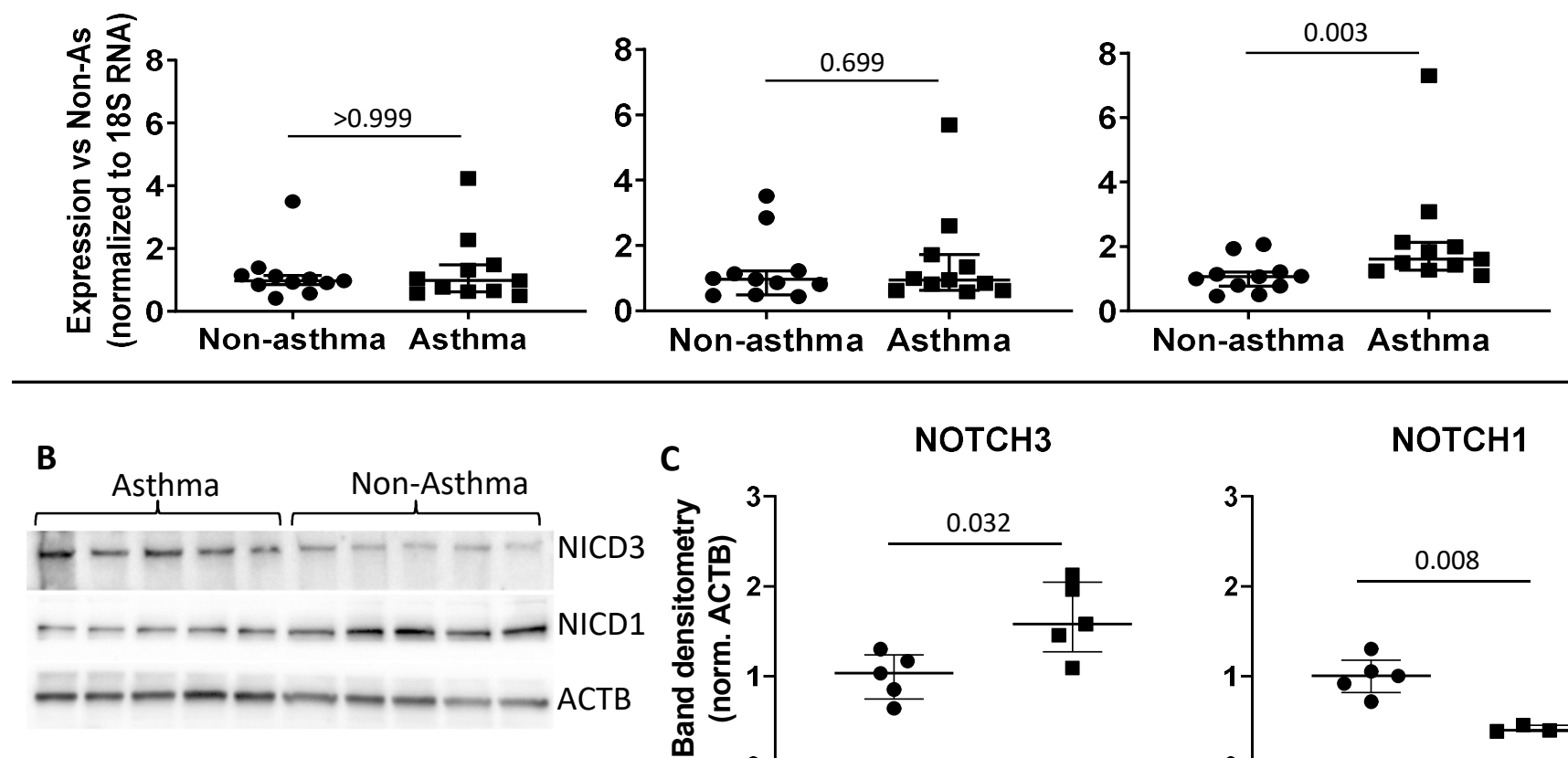

C NOTCH3

NOTCH1
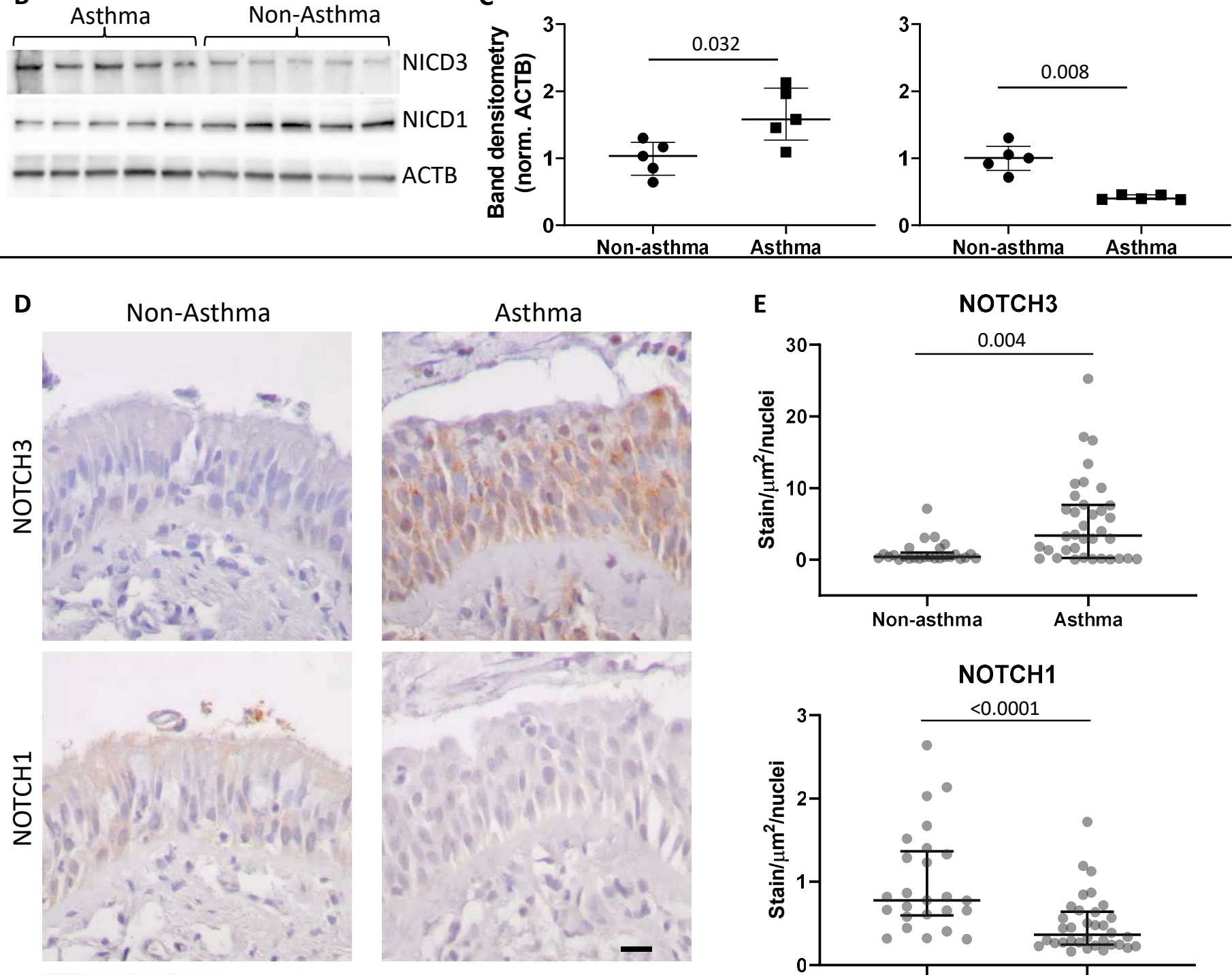

E

NOTCH3
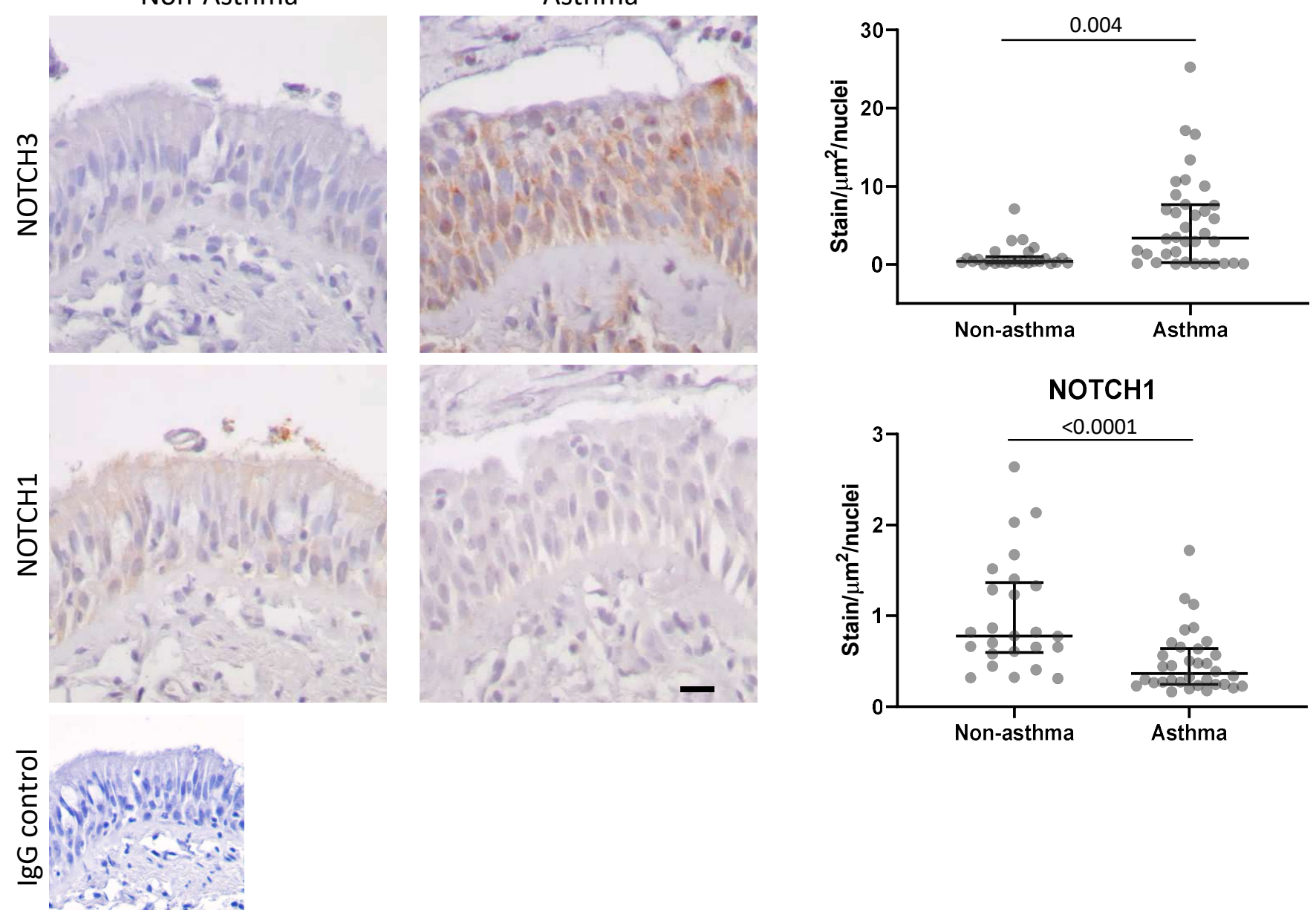
Non-Asthmatic DMSO

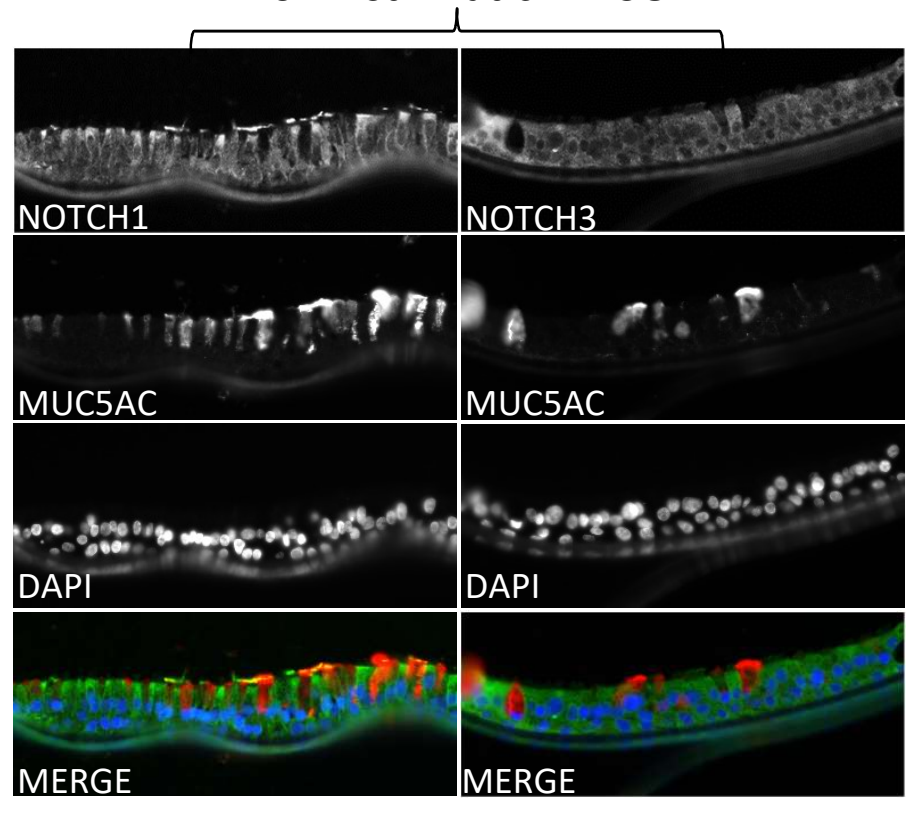

Asthmatic DMSO

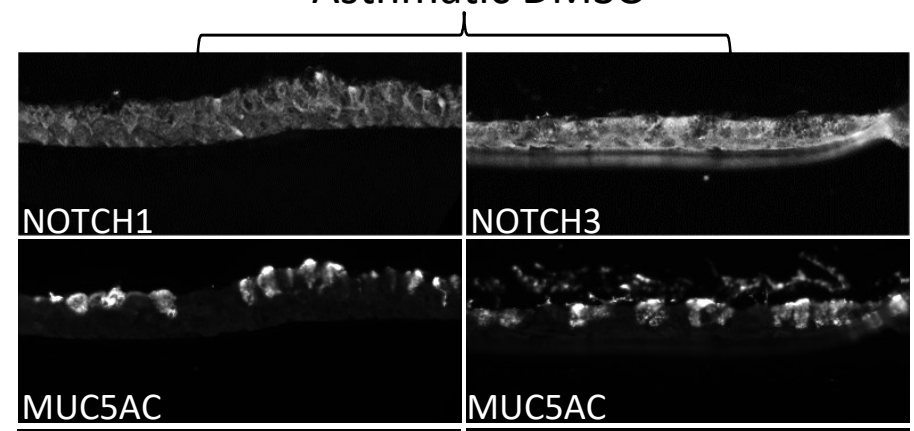

MUC5AC
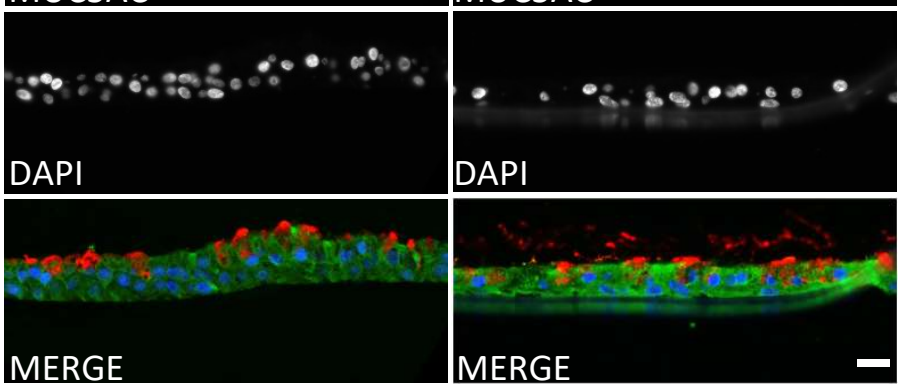

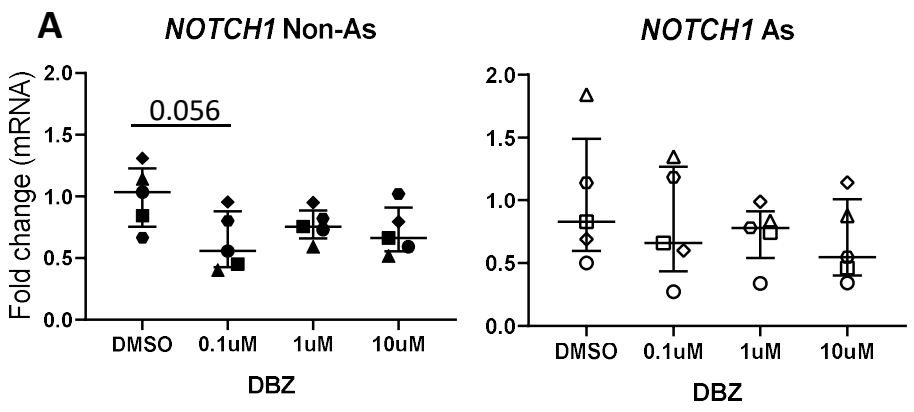

B

DBZ
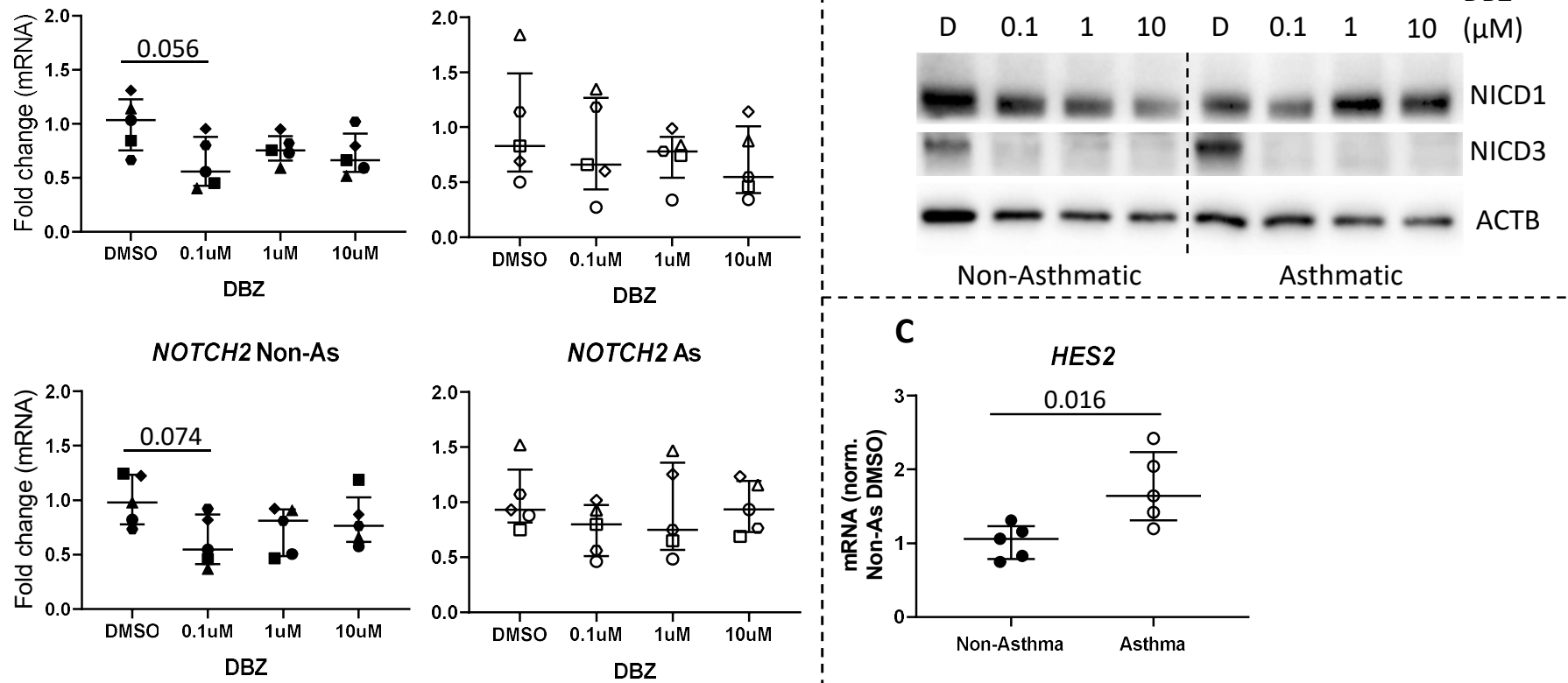

NOTCH2 As

C

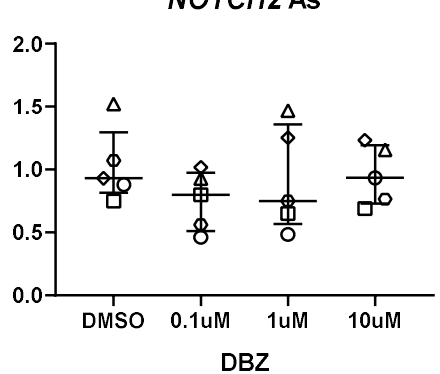

HES2

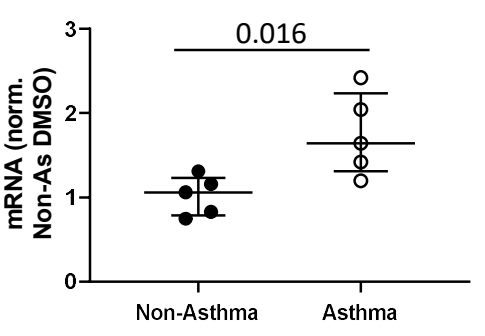

NOTCH3 Non-As

NOTCH3 As
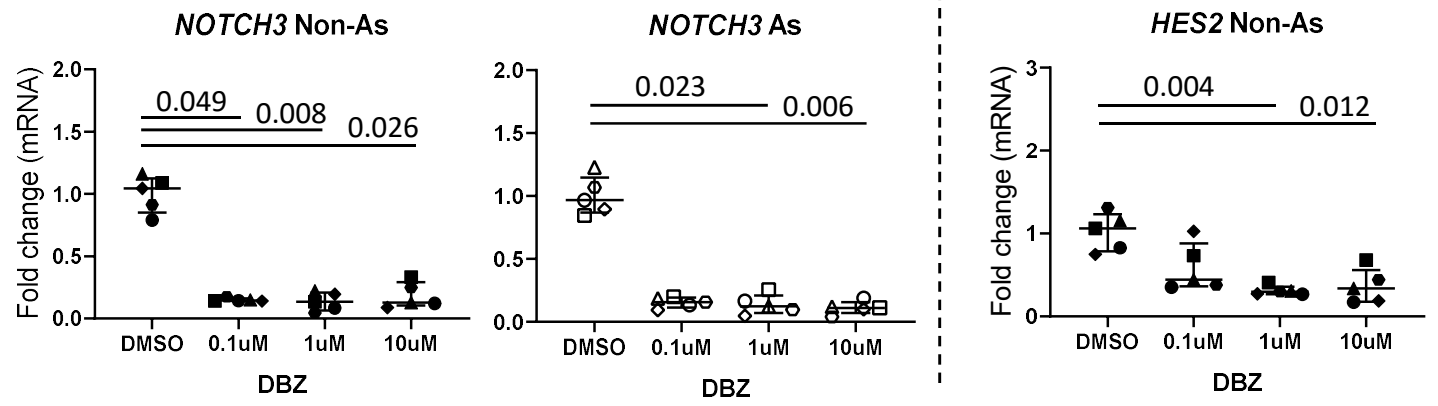

HES2 As

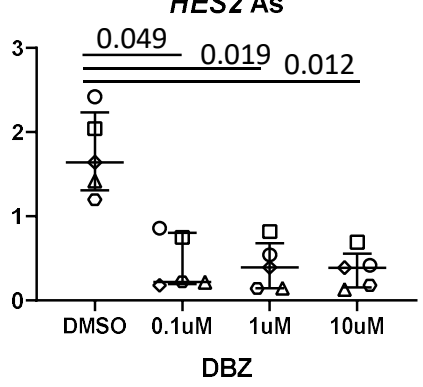

Figure 3 
A

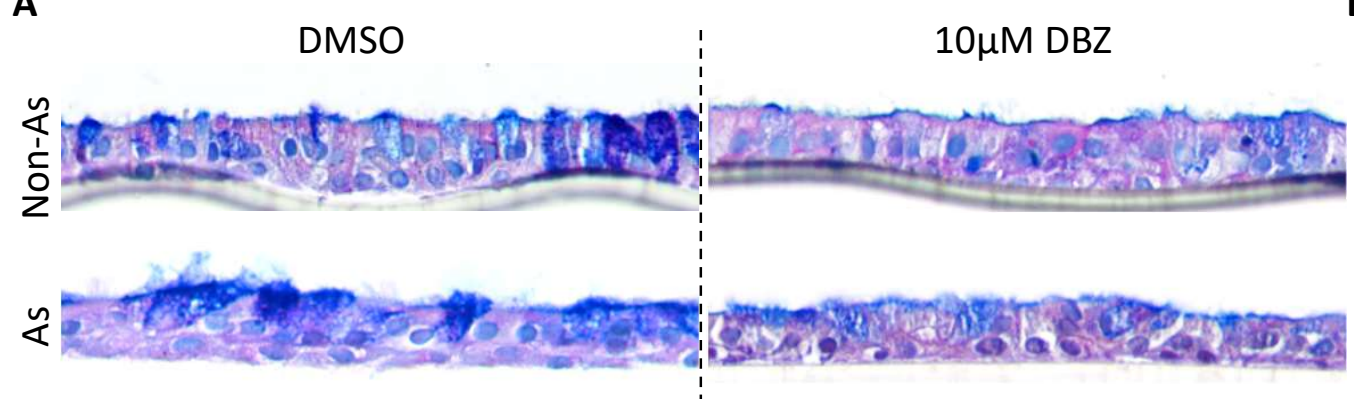

C
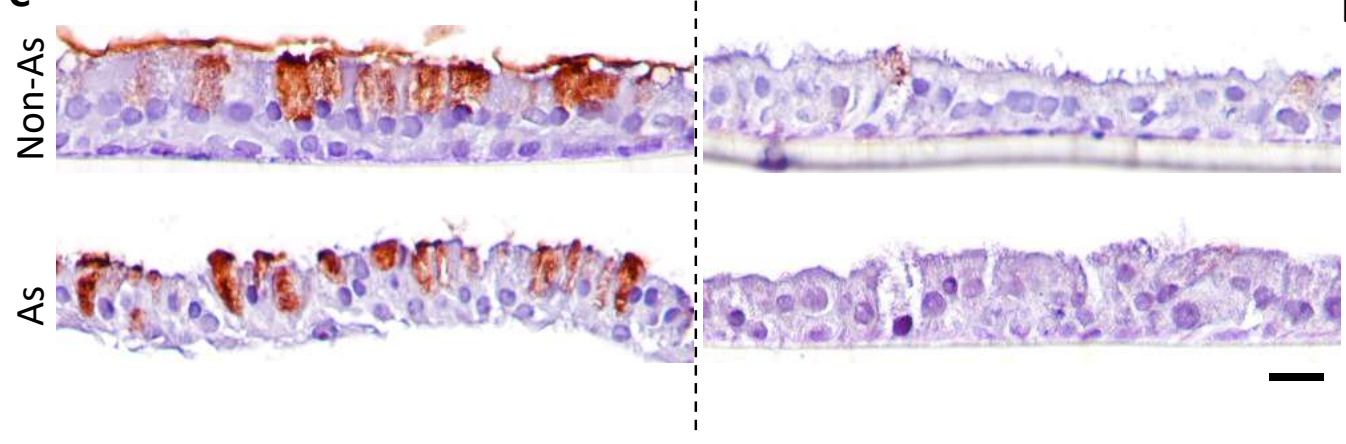

B

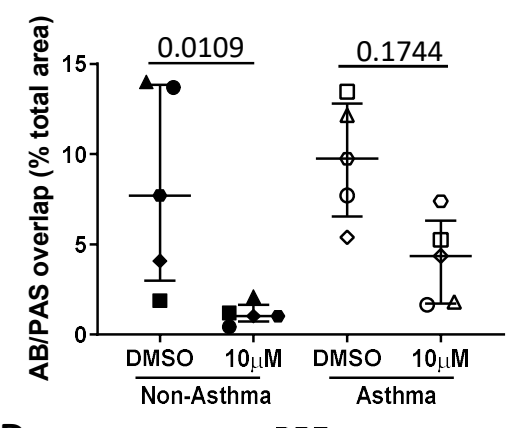

DBZ

$\frac{0.008}{\square}$

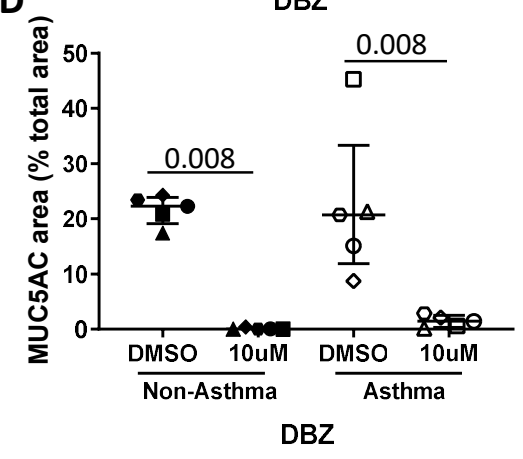

Figure 4 
A MUC5AC Non-As

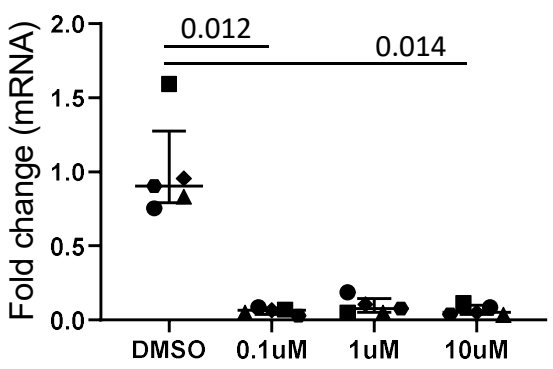

DBZ
MUC5AC As

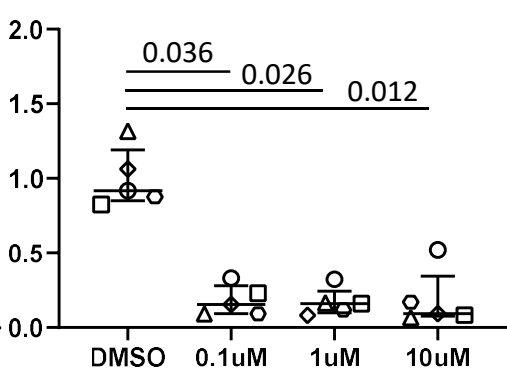

DBZ
D

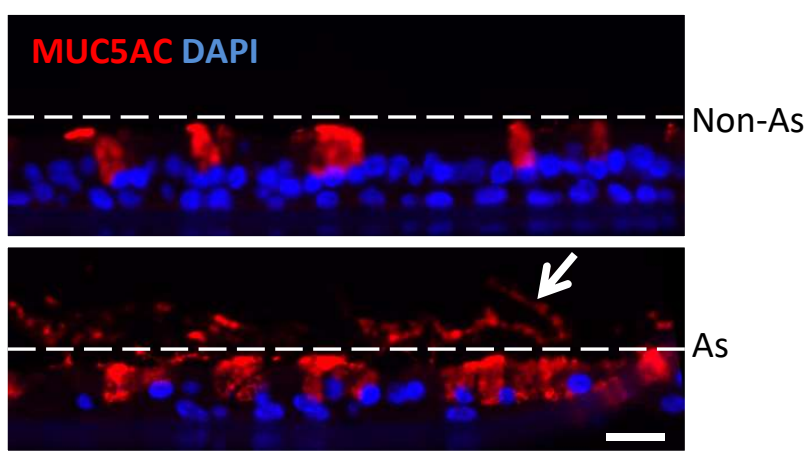

B

MUC5AC Non-As

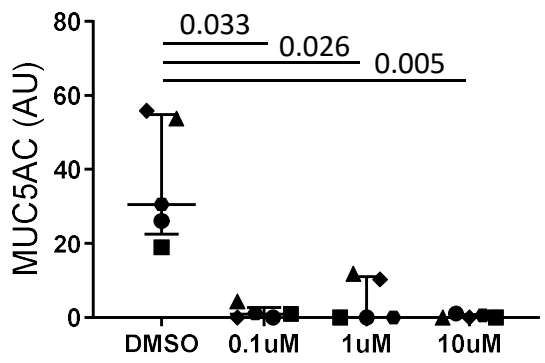

DBZ

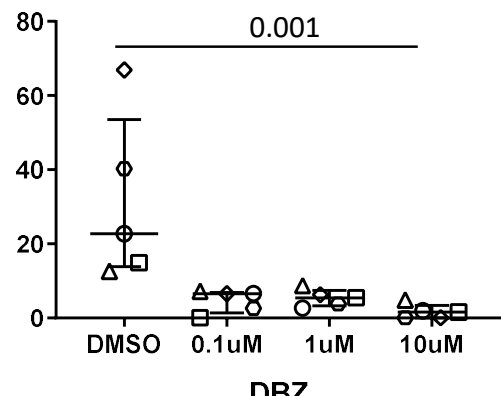

C

SPDEF Non-As
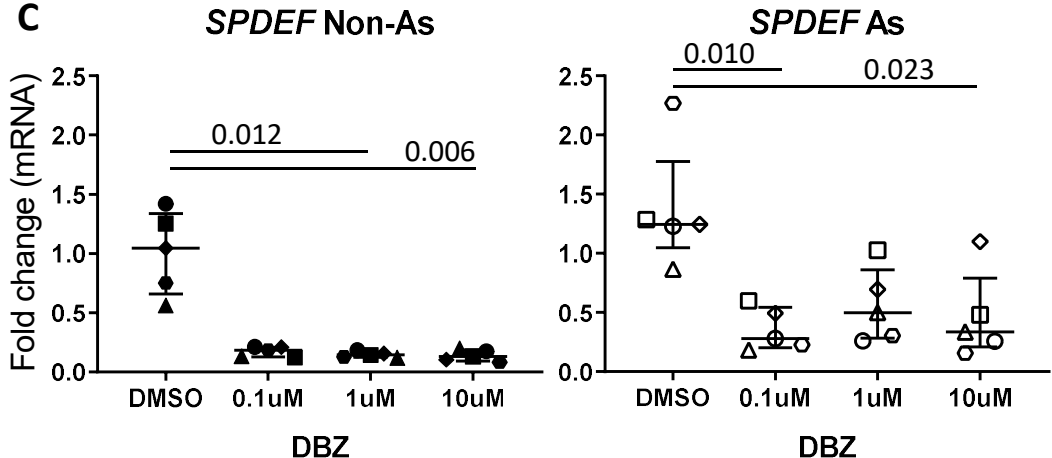

Figure 5 


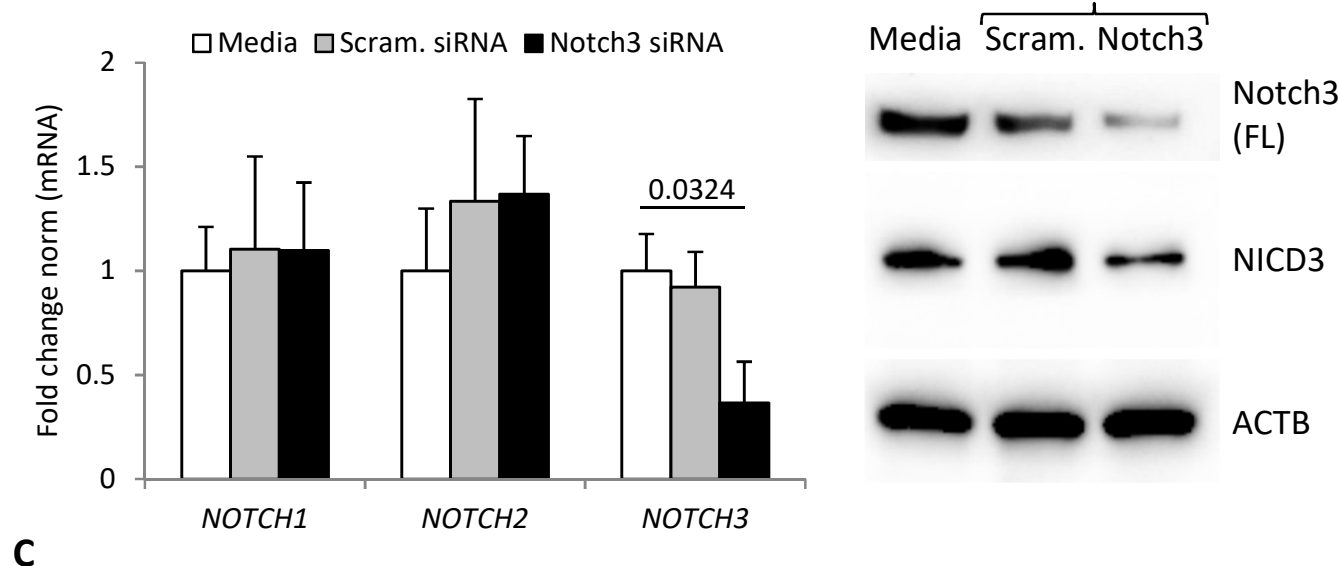

C
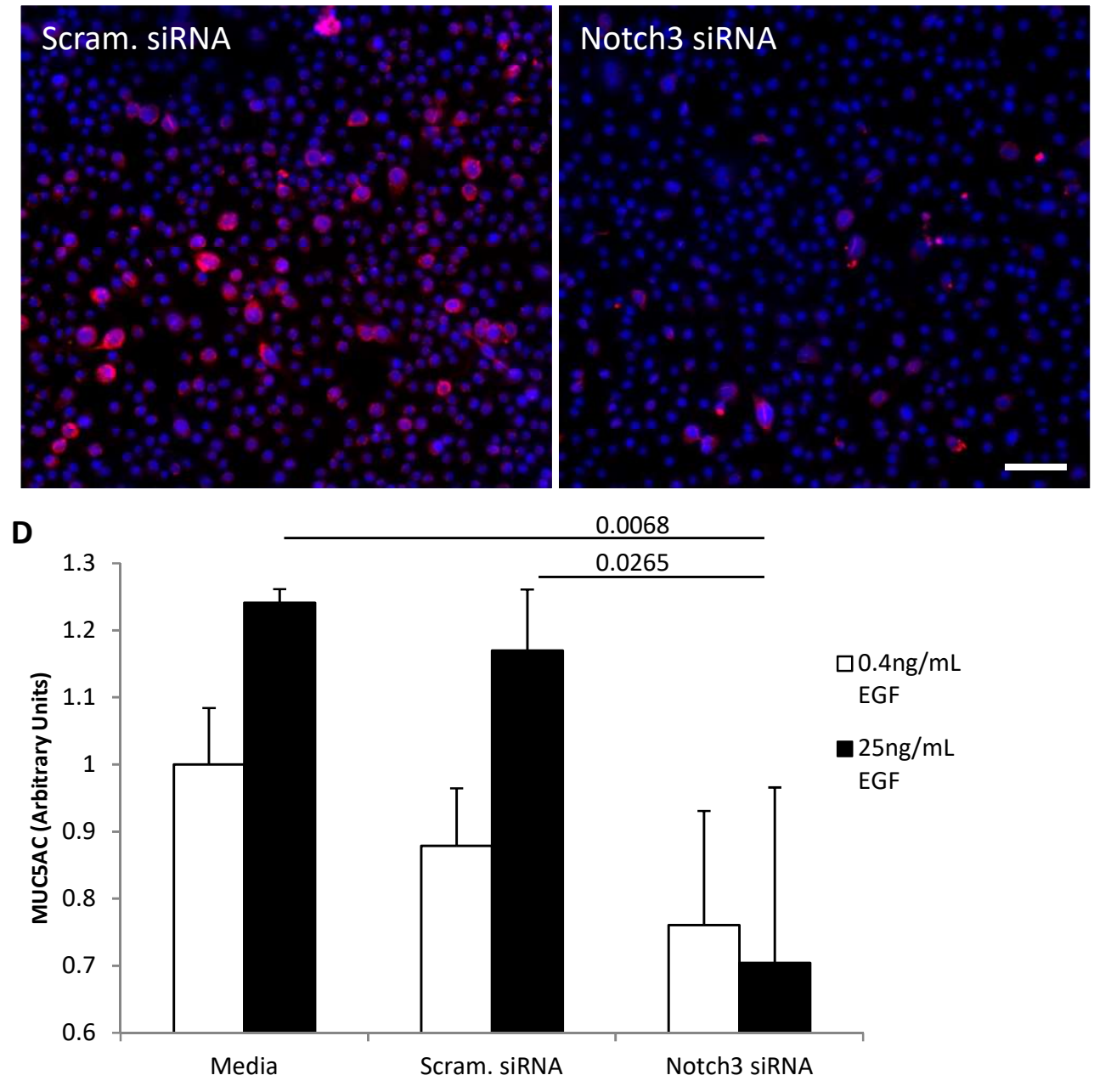

Figure 6 


\section{Online Data Supplement:}

\section{Blocking Notch3 Signaling Abolishes MUC5AC Production in Airway Epithelial Cells from Asthmatics}

Andrew T Reid, Kristy S Nichol, Punnam Chander-Veerati, Fatemeh Moheimani, Anthony Kicic, Stephen M Stick, Nathan W Bartlett, Chris L Grainge, Peter A B Wark, Philip M Hansbro, Darryl A Knight

\section{Additional Materials and Methods:}

pBEC Cell Culture and Pharmacological Inhibition: Prior to culture at the ALI, pBECs were seeded at a density of $1.8 \times 10^{5}$ cells $/ \mathrm{cm}^{2}$ onto transwell polymer inserts (transparent, $0.4 \mu \mathrm{m}$ pore; Corning, NY, USA) at passage two. Cells were grown in low-glucose Dulbecco's Modified Eagle's Medium (DMEM; Sigma-Aldrich, MO, USA) and an equivalent volume bronchial epithelial cell basal medium (BEBM; Lonza) containing; hydrocortisone (Lonza; CC-4031F), insulin (bovine) (Lonza; CC-4021F), Epinephrine (Lonza; CC-4221F), bovine pituitary extract (Lonza; CC-4009F), transferrin (Lonza; CC4205F), ethanolamine ( $80 \mu \mathrm{M}$ final), $\mathrm{MgCl}_{2}(0.3 \mathrm{mM}$ final $), \mathrm{MgSO}_{4}(0.4 \mathrm{mM}$ final $)$, bovine serum albumin $(0.5 \mathrm{mg} / \mathrm{mL})$, penicillin-streptomycin (100U/mL-100 $\mu \mathrm{g} / \mathrm{mL}$ final) and Amphotericin B $(2.5 \mu \mathrm{g} / \mathrm{mL}$ final). This 50:50 medium was supplemented with, all-trans retinoic acid (30ng/mL; Sigma-Aldrich) and recombinant human epidermal growth factor (rhEGF, 10ng/mL; Bioscientific, NSW, Australia). Cells were lifted to the ALI when confluent, apical medium was removed and basolateral medium was replaced with 50:50 media (30ng/mL retinoic acid, $0.4 \mathrm{ng} / \mathrm{mL} \mathrm{rhEGF}$ ). Basolateral medium was changed every 2-3 days. Trans-epithelial electrical resistance (TEER) measurements were made using an epithelial voltohmmeter (EVOM2; WPI, FL, USA) and apical surface washes were performed 
every week using $500 \mu \mathrm{L} 37^{\circ} \mathrm{C}$ Dulbecco's phosphate buffered saline (DPBS; GE Healthcare, Little Chalfont, UK).

Dibenzazepine Treatment: Basolateral medium was replaced with 50/50 medium (30ng/mL retinoic acid, $25 \mathrm{ng} / \mathrm{mL}$ rhEGF $)$ containing $0.1,1,10 \mu \mathrm{M} \mathrm{DBZ}$ or vehicle control $(0.02 \% \mathrm{v} / \mathrm{v}$ DMSO; Sigma). Apical surface fluid was aspirated every 24 hours, while basolateral medium was aspirated and replaced at 48 hours. All apical and basolateral fluid was stored at $-80^{\circ} \mathrm{C}$. At 96 hours cell were harvested for RNA, protein or fixed in 10\% Formalin (Lomb Scientific, NSW, Australia) for histology.

BCI-Ns1.1 Cell Culture and siRNA Transfection: Transfection complexes containing predesigned Silencer select Notch3 siRNA (s9640; Thermo Fisher Scientific, MA, USA), Silencer Select negative control siRNA (4390843; Thermo Fisher Scientific), or media control were prepared using siPORT NeoFX (Thermo Fisher Scientific) transfection agent according to manufacturer's instructions. Briefly, suspensions of BCI-NS1.1 cells $(n=4)$ were incubated in a mixture of siPORT NeoFX transfection agent (Thermo Fisher Scientific) and $50 \mathrm{nmol} / \mathrm{L}$ siRNA oligonucleotides in Opti-MEM I (Thermo Fisher Scientific).

Human lung tissue Immunohistochemistry (IHC) and colorimetry: Sections were subjected to immunohistochemical staining and all steps were conducted simultaneously. Briefly, sections were deparaffinised in xylene followed by rehydration through decreasing ethanol concentrations. Following antigen retrieval and peroxidase quenching, slides were blocked in Tris-buffered saline ( $\mathrm{pH}$ 7.4) containing $0.05 \% \mathrm{v} / \mathrm{v}$ Tween-20 (Sigma-Aldrich) (TBS-T) 1\% w/v Casein (Thermo Fisher Scientific). Slides were incubated overnight at $4^{\circ} \mathrm{C}$ with rabbit polyclonal anti-Notch3 $(4 \mu \mathrm{g} / \mathrm{mL})(\mathrm{ab} 23426 ;$ Abcam, Cambridge, UK), rabbit polyclonal anti-Notch1 $(4 \mu \mathrm{g} / \mathrm{mL})(\mathrm{ab} 27526$; 
Abcam) in Tris-buffered saline (pH 7.4) containing 0.05\% v/v Tween-20 (Sigma-Aldrich) (TBST). Goat anti-rabbit secondary conjugated to horseradish peroxidase $(2 \mu \mathrm{g} / \mathrm{mL})$ (ab6721; Abcam) was incubated for 1 hour at room temperature prior to 3,3'-diaminobenzidine tetrahydrochloride $(\mathrm{DAB}+)$ chromogen development (Agilent Technologies, CA, USA). Sections were counterstained with Mayer's hematoxylin (Agilent Technologies). Rabbit IgG isotype control antibody (ab125938) was used as negative control. Sections were mounted and photographed using a phase contrast microscope (Eclipse E400; Nikon, Tokyo, Japan) with attached high resolution camera (Digital Sight DS-5m, Nikon). A minimum of 5 images were taken of small and medium sized airways per section (between 1 and 5mm inner diameter) with identical white balancing, contrast ring position and exposure times. Measurements of airway epithelial cell area were made using open-source imageJ software (ImageJ/NIH, MD, USA) and all non-epithelial cell areas were removed from subsequent analysis. Epithelial regions were subjected to colour deconvolution as previously described (E1). Total $\mathrm{DAB}+$ (brown) positive area of each epithelial image was recorded and divided by the total area of the respective epithelium. So as to account for obliquely cut sections with more cell layers, this value was divided by the total number of nuclei which were counted manually. Mean stain $/ \mu \mathrm{m}^{2} /$ nuclei values were normalized to 1 for non-asthmatic samples for each antibody. Non-parametric Kruskal-Wallis test was used to determine statistical significance.

Air-liquid interface protein extraction and western blotting: Following endpoints for each ALI culture, trans-well membranes/ cells were washed briefly with PBS, cut in half, and placed in icecold lysis buffer (50mM Tris- $\mathrm{HCl}(\mathrm{pH} 7.4), 150 \mathrm{mM} \mathrm{NaCl}, 1 \mathrm{mM}$ EDTA, $1 \%$ triton X-100, 0.1\% sodium dodecyl sulfate, $0.5 \%$ sodium deoxycholate) containing protease inhibitor cocktail (Roche, Basel, Switzerland) for 30min. Following incubation trans-well membranes were removed and 
cellular protein samples were aspirated following centrifugation. Samples were electrophoresed on $7.5 \%$ polyacrylamide gels (Bio-Rad, CA, USA) after which protein was transferred onto Immobilon polyvinylidene difluoride (PVDF) (Merck Millipore, MA, USA) or Amersham Protran nitrocellulose (GE Healthcare) membranes. Membranes were blocked and subsequently incubated with primary antibodies; anti-NOTCH3 $(0.2 \mu \mathrm{g} / \mathrm{mL})$, anti-NOTCH1 $(0.2 \mu \mathrm{g} / \mathrm{mL})$, or anti- $\beta$ actin (ab8227; Abcam) $(0.05 \mu \mathrm{g} / \mathrm{mL})$. Membranes were incubated with goat anti-rabbit (ab6721; Abcam) or rabbit anti-mouse (ab6728; Abcam) secondary antibodies conjugated to horseradish peroxidase (HRP). Protein bands were visualized using SuperSignal West Femto (Thermo Fisher Scientific) chemiluminescence (ChemiDoc MP, Bio-Rad).

\section{IHC, immunofluorescence (IF) and alcian blue/PAS staining in ALI cultures: ALI}

membranes were coated apically with $2 \% \mathrm{w} / \mathrm{v}$ low melting point agarose to protect cells.

Samples were subjected to standard histological ethanol/ xylene dehydration followed by paraffin embedding. IHC was performed on $5 \mu \mathrm{m}$ thick sections of membrane/cells as previously detailed for human airway sections, except mouse monoclonal anti-MUC5AC (ab3649; Abcam) primary antibody was used at $2 \mu \mathrm{g} / \mathrm{mL}$. For IF, ALI sections were exposed to direct white light for $>24$ hours to quench any endogenous fluorescence. Samples were deparaffinised, rehydrated and subjected to antigen retrieval as above. Samples were blocked with $10 \% \mathrm{v} / \mathrm{v}$ goat serum and 3\% bovine serum albumin (BSA) (GE Healthcare) in TBS-T, followed by overnight incubation in anti-NOTCH3, anti-NOTCH1 in combination with anti-MUC5AC. Alexa-fluor 488conjugated donkey anti-rabbit (A-21203: Invitrogen, CA, USA) or 594-conjugated donkey antimouse secondary antibody (A-21203; Invitrogen) and mounting media with DAPI (ProLong Gold; Thermo Fisher Scientific) were used for fluorescent visualization of NOTCH, MUC5AC and nuclei respectively. Images were obtained using an Axio Imager M2 automated fluorescence 
microscope (Carl Zeiss AG, Oberkochen, Germany) with identical capture settings/processing for all images. Standard Alcian blue pH2.5 and Periodic Acid Schiff (PAS) staining (AB/PAS) was performed on ALI sections to observe total mucin content. For IHC and AB/PAS, a minimum of 5 images were taken randomly across sections of each ALI membrane and mean value recorded. This was repeated for 5 donor replicates with identical white balancing, contrast ring position and exposure times (E2). Measurements of airway epithelial cell area were made using open-source imageJ software (ImageJ/NIH, MD, USA) and all non-epithelial cell areas were removed from subsequent analysis. Epithelial regions were subjected to identical colour deconvolution and thresholding for $\mathrm{DAB}$ or $\mathrm{AB} / \mathrm{PAS}$ overlap to obtain distinct areas with positive stain. The positive stain area of each epithelial image was recorded and divided by the total area of the respective epithelium and expressed as a percentage (\% total area). MannWhitney U test was used to determine statistical significance.

Real-time quantitative RT-qPCR: Total RNA was extracted from cells using the RNeasy kit (Qiagen, Hilden, Germany) and cDNA was prepared as previously described on a T100 Thermal Cycler (Bio-Rad) (E3). Quantitative PCR (qPCR) was performed on a Mastercycler Realplex2 (Eppendorf AG, Hamburg, Germany) using Taqman gene expression mastermix (Thermo Fisher Scientific). Target mRNA expression was normalized to $18 \mathrm{~S}$ ribosomal RNA (18S rRNA) (4318839; Thermo Fisher Scientific) as previously described (E4). Taqman ${ }^{\circledR}$ Gene Expression Assay primers (4331182; Thermo Fisher Scientific) were utilized targeting NOTCH1 (Hs01062014_m1), NOTCH2 (Hs01050702_m1), NOTCH3 (Hs01128537_m1), NOTCH4 (Hs00965889_m1), SPDEF (Hs00171942_m1), HES2 (Hs01021800_g1) and MUC5AC (Hs00873651_m1) for qPCR reactions. All qPCR results are presented as mean log2 fold change relative to control with statistics performed on $\Delta \Delta \mathrm{Ct}$ from independent biological replicates (E5). 
MUC5AC ELISA: As purified standards of MUC5AC are commercially unavailable, MUC5ACrich protein was obtained from cultures of Calu-3 human lung adenocarcinoma epithelial cells grown to ALI (E6). Serial dilutions were made of Calu-3 apical surface fluid and linear MUC5AC standard curve was confirmed (data not shown). Mucin-containing ALI apical surface fluid was incubated with $500 \mu \mathrm{L}$ warm PBS and lightly agitated before aspiration. Apical washes were collected every 24 hours and data is presented as the relative amount of MUC5AC secreted across sequential 24 hour time-windows (i.e. 0-24, 24-48, 48-72, and 72-96h). Aspirates and standards were agitated at $1000 \mathrm{rpm}$ at $42^{\circ} \mathrm{C}$ to homogenize consistency, coated into multi-well plates (Thermo Fisher Scientific) and dried overnight in $37^{\circ} \mathrm{C}$ oven (Benchmark Scientific, NJ, USA). After washing, plates were blocked (5\% w/v BSA in PBS) and incubated with biotinylated mouse monoclonal anti-MUC5AC (ab79082; Abcam) $(0.2 \mu \mathrm{g} / \mathrm{mL})$ for 1 hour. Plates were incubated with Streptavidin-HRP conjugate (Thermo-Fisher Scientific) and developed using 3,3',5,5'tetramethylbenzidine (TMB; Thermo-Fisher Scientific). 


\section{References}

E1. Walters MS, Gomi K, Ashbridge B, Moore MAS, Arbelaez V, Heldrich J, Ding B-S, Rafii S, Staudt MR, Crystal RG. Generation of a human airway epithelium derived basal cell line with multipotent differentiation capacity. Respir Res 2013; 14: 135-135.

E2. Singanayagam A, Glanville N, Girkin JL, Ching YM, Marcellini A, Porter JD, Toussaint M, Walton RP, Finney LJ, Aniscenko J, Zhu J, Trujillo-Torralbo M-B, Calderazzo MA, Grainge C, Loo S-L, Veerati PC, Pathinayake PS, Nichol KS, Reid AT, James PL, Solari R, Wark PAB, Knight DA, Moffatt MF, Cookson WO, Edwards MR, Mallia P, Bartlett NW, Johnston SL. Corticosteroid suppression of antiviral immunity increases bacterial loads and mucus production in COPD exacerbations. Nat Commun 2018; 9: 2229.

E3. Schuliga M, Jaffar J, Berhan A, Langenbach S, Harris T, Waters D, Lee PVS, Grainge C, Westall G, Knight D, Stewart AG. Annexin A2 contributes to lung injury and fibrosis by augmenting factor Xa fibrogenic activity. Am J Physiol Lung Cell Mol Physiol 2017; 312: L772L782.

E4. Schmittgen TD, Livak KJ. Analyzing real-time PCR data by the comparative C(T) method. Nat Protoc 2008; 3: 1101-1108.

E5. Kreda SM, Okada SF, van Heusden CA, O'Neal W, Gabriel S, Abdullah L, Davis CW, Boucher RC, Lazarowski ER. Coordinated release of nucleotides and mucin from human airway epithelial Calu-3 cells. J Physiol 2007; 584: 245-259.

E6. Bartlett NW, Walton RP, Edwards MR, Aniscenko J, Caramori G, Zhu J, Glanville N, Choy KJ, Jourdan P, Burnet J, Tuthill TJ, Pedrick MS, Hurle MJ, Plumpton C, Sharp NA, Bussell JN, 
Swallow DM, Schwarze J, Guy B, Almond JW, Jeffery PK, Lloyd CM, Papi A, Killington RA, Rowlands DJ, Blair ED, Clarke NJ, Johnston SL. Mouse models of rhinovirus-induced disease and exacerbation of allergic airway inflammation. Nat Med 2008; 14: 199-204. 
Supplementary Figures

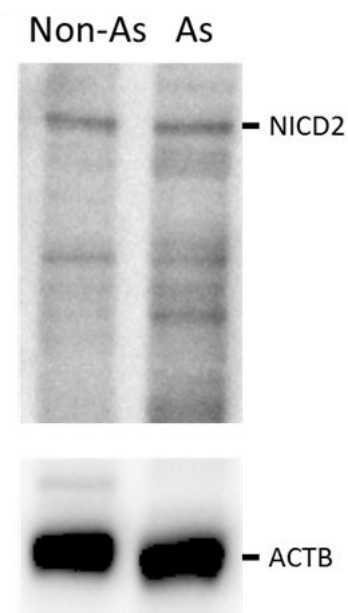

Figure E1: Notch2 intracellular domain (NICD2) protein in ALI pBECs differentiated to day25 and immunoblotted.

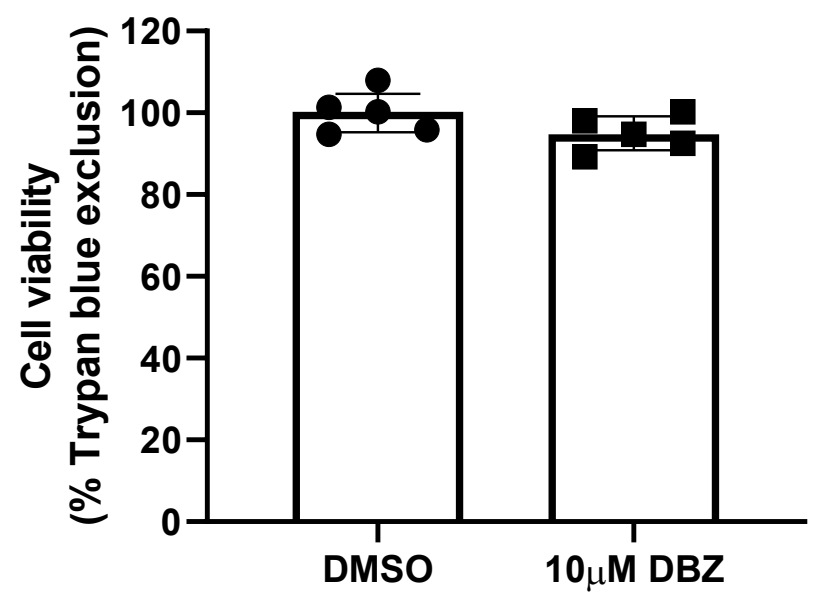

Figure E2: Cell viability of ALI pBECs treated with $10 \mu \mathrm{M} \mathrm{DBZ}$ for 96 hours. Cells were trypsinized and assessed via $0.4 \%$ trypan blue exclusion. 


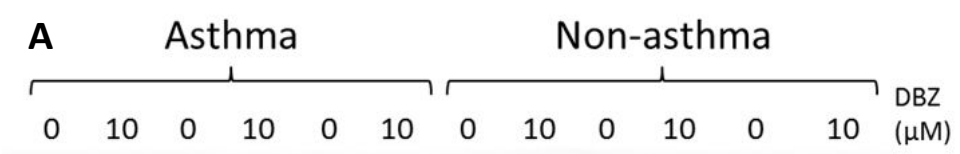

CLCA1

(secretory)

B

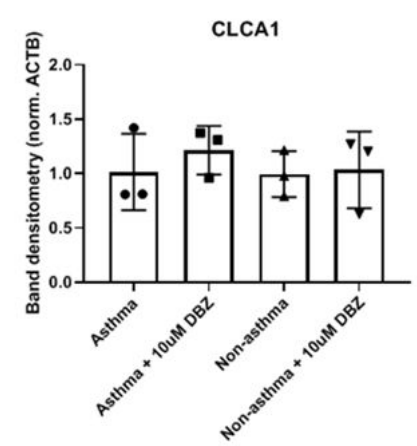

Ac. $\beta$-tubulin

(ciliated)

ACTB

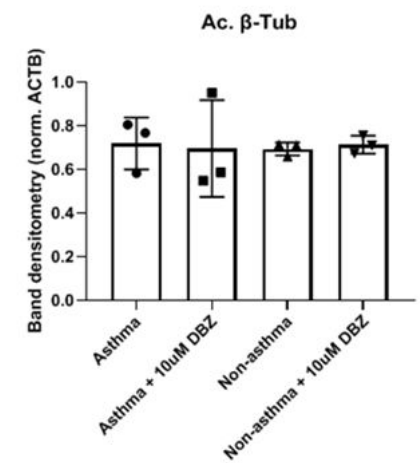

Figure E3: Cell types of differentiated ALI pBECs (Day29) do not change following treatment with $10 \mu \mathrm{M}$ DBZ. (A) Western blots targeting specific markers of goblet cells (chloride channel accessory 1 protein: CLCA1) and ciliated cells (acetylated $\beta$-tubulin: Ac. B-Tub). (B) Densitometry for CLCA1 and Ac. B-Tub normalized to $\beta$-actin (ACTB). 